Portland State University

PDXScholar

3-17-2004

\title{
Adult and Juvenile Sexual Offenders: The Use of Violence and Fantasies
}

Megan N. Carter

Portland State University

Follow this and additional works at: https://pdxscholar.library.pdx.edu/open_access_etds

Part of the Child Psychology Commons, and the Other Psychology Commons Let us know how access to this document benefits you.

\section{Recommended Citation}

Carter, Megan N., "Adult and Juvenile Sexual Offenders: The Use of Violence and Fantasies" (2004). Dissertations and Theses. Paper 1719.

https://doi.org/10.15760/etd.1718

This Thesis is brought to you for free and open access. It has been accepted for inclusion in Dissertations and Theses by an authorized administrator of PDXScholar. Please contact us if we can make this document more accessible: pdxscholar@pdx.edu. 


\section{THESIS APPROVAL}

The abstract and thesis of Megan N. Carter for the Master of Science in Psychology were presented March 17, 2004, and accepted by the thesis committee and the department.

COMMITTEE APPROVALS:

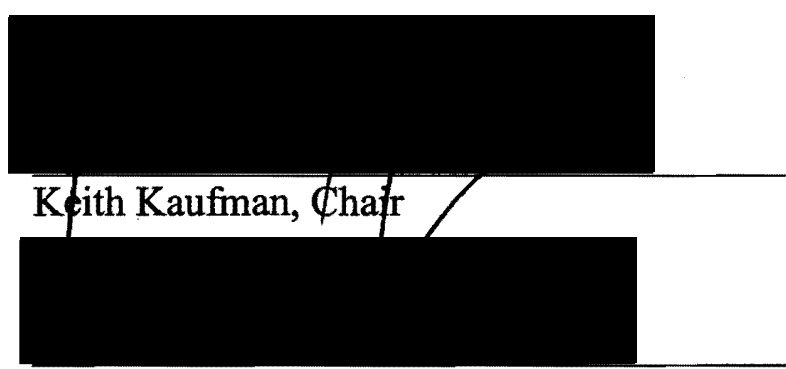

Eric Mankowski

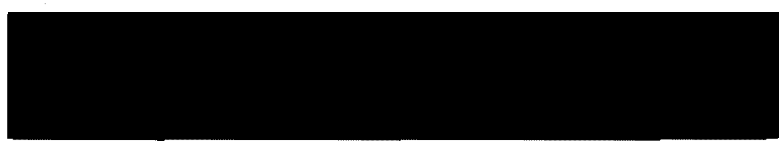

Cynthia Mohr

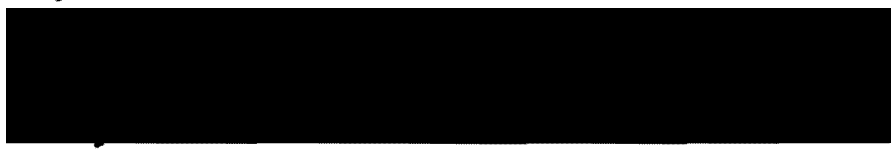

Tom Crofoot

Representative of the Office of Graduate Studies

DEPARTMENT APPROVAL:

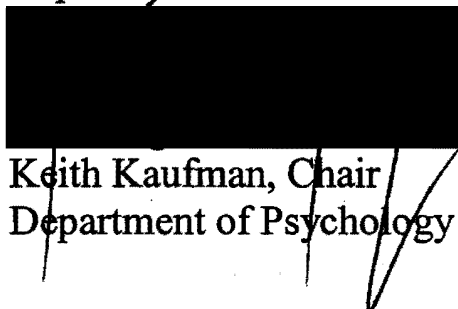




\begin{abstract}
An abstract of the thesis of Megan N. Carter for the Master of Science in Psychology presented March 17, 2004.
\end{abstract}

Title: Adult and juvenile sexual offenders: The use of violence and fantasies

Child sexual abuse (CSA) has been recognized as a widespread and devastating problem in our society. Definitional challenges result in a broad range of prevalence rates for CSA varying from $6 \%$ to $62 \%$ for females and $3 \%$ to $31 \%$ for males (Finkelhor, Araji, Baron, Browne, Peters, \& Wyatt, 1986). Although CSA affects our nation's children in epidemic proportions, researchers have found little conclusive evidence regarding CSA precursors.

One promising area for exploring the etiology of CSA may be the differential patterns of sexual fantasies in juvenile and adult sex offenders. Abel, Becker, Mittleman, Cunningham-Rathner, Rouleau and Murphy (1987) found that more than $40 \%$ of non-familial child molesters reported the development of deviant sexual fantasies prior to sexually offending. Despite variations in offender subgroups, Marshall, Barbaree and Eccles (1991) found that $22 \%$ of the offenders experienced deviant fantasies prior to their first sexual offense. Unfortunately, the literature in this area has been quite limited despite its potential.

Understanding offender similarities and differences in adult and juvenile populations may be important due to the large proportion of the offender 
population who begin sexually offending as juveniles and due to the treatment modalities that may be implemented for developmentally different offenders. As many as $50 \%$ of adult sex offenders have reported sexually deviant behavior beginning in adolescence (Becker, 1988; Ferhenbach, Smith, Monastersky \& Deisher, 1986; Marshall, Barbaree, \& Eccles, 1991). Juveniles have also been identified as perpetrators in more than half of all cases (Fehrenbach, Smith, Monastersky, \& Deisher,1986).

This study investigates the relationship between offenders' sexual fantasies and their use of physical force to sexually offend. This investigation was also designed to examine the similarities and differences between adult and adolescent sexual offenders on these dimensions. Findings reveal an empirical relationship between offenders' fantasies and behaviors in sexual offending. It is anticipated that additional knowledge regarding potential relationships between fantasies and behaviors will assist in assessing and intervening with accused and convicted sexual offenders. Potential implications for clinical assessment and intervention into sexual abuse are discussed as well as the potential for understanding maintenance factors in the continuation of sexual abuse. 


\title{
ADULT AND JUVENILE SEXUAL OFFENDERS:
}

\section{THE USE OF VIOLENCE AND FANTASY}

\author{
by
}

MEGAN N. CARTER

A thesis submitted in partial fulfillment of the requirements for the degree of

\section{MASTER OF SCIENCE in PSYCHOLOGY}

\section{Portland State University}

2004 
Adult and Juvenile Sexual Offenders i

Table of Contents

List of Tables $\quad$ ii

List of Figures $\quad$ iii

Introduction $\quad 1$

$\begin{array}{ll}\text { Theories of Child Sexual Abuse } & 17\end{array}$

$\begin{array}{ll}\text { Fantasies } & 31\end{array}$

$\begin{array}{ll}\text { Violence and Sexual Offending } & 38\end{array}$

Violence and Fantasies $\quad 41$

$\begin{array}{ll}\text { Current Study } & 43\end{array}$

Method 44

$\begin{array}{ll}\text { Results } & 51\end{array}$

$\begin{array}{ll}\text { Discussion } & 61\end{array}$

$\begin{array}{ll}\text { References } & 79\end{array}$ 


\section{List of Tables}

Table 1. Sexual Fantasy Questionnaire Scale Scores (MANOVA) 52

Table 2. Sexual Fantasy Questionnaire Scale (ANOVA) 52

Table 3. Violence Scale Scores (MANOVA) 53

Table 4. Violence Scale (ANOVA) 54

Table 5. Standardized Coefficients and Correlations of 55 Predictor Variables With the First Discriminant Functions

Table 6, Standardized Coefficients and Correlations of

Predictor Variables with the Two Discriminant Functions 
Adult and Juvenile Sexual Offenders iii

\section{List of Figures}

Figure 1. Classical Conditioning and Sexually Offending 23

Figure 2. Operant Conditioning and Sexual Offending 24

$\begin{array}{ll}\text { Figure 3. Arousal conditioning } & 24\end{array}$

Figure 4. Juvenile Group Centroids $\quad 56$

Figure 5. Adult Group Centroids $\quad 59$ 
Adult and Juvenile Sexual Offenders:

The Use of Violence and Fantasies

Introduction

Child sexual abuse (CSA) is a widespread and devastating social problem. The American Medical Association has identified child sexual abuse as a "silent, violent epidemic" (DHHS, 1991). Although there is increasing awareness of CSA, the exact numbers of victims and perpetrators are difficult to determine due to a variety of methodological issues. Definitional challenges result in a broad range of prevalence rates for child sexual abuse varying from $6 \%$ to $62 \%$ for females and $3 \%$ to $31 \%$ for males (Finkelhor, Araji, Baron, Browne, Peters, \& Wyatt, 1986). At the same time, it is generally accepted that official records underestimate the actual number of child sexual abuse cases due to underreporting and these definitional concerns (Laws \& O’Donohue, 1997). Given this definitional inconsistency within the research community, the exact number of children who experience child sexual abuse each year is impossible to determine although the numbers appear to be quite large. Despite the epidemic proportion of children who experience child sexual abuse, research into the etiology, prevention and intervention approaches are in their infancy. Further research is needed to better understand the precursors and maintenance factors related to this pervasive social problem. 


\section{Prevalence and Definitions of CSA}

There is a lack of consensus as to what constitutes "child sexual abuse." The varied definitions used for research within the field directly contributes to the difficulties establishing prevalence rates for CSA. Gail Ryan (1997) defined sexually abusive behavior as "any sexual interaction with person(s) of any age that is perpetrated (1) against the victim's will, (2) without consent, or (3) in an aggressive, exploitative, manipulative, or threatening manner." Some researchers include only contact offenses (i.e., where the perpetrator physically touches the victim) while others include contact as well as non-contact (e.g., exposing one's genitalia to a victim) offenses when gathering information regarding the prevalence of CSA (Finkelhor et al., 1986). A number of investigators have excluded adolescents in their samples as victims or perpetrators despite research demonstrating that adolescents perpetrate child sexual abuse at high rates as well as reporting their own sexual victimization (Salter, 1988). As would be expected, research utilizing broader definitions of CSA (i.e., non-contact) has yielded higher rates of CSA reporting while more conservative definitions tend to result in lower CSA rates (Finkelhor et al., 1986).

Other difficulties may lie in the retrospective nature of most child sexual abuse prevalence studies. In many cases, research participants have been asked to recall events that occurred up to decades earlier. Yet, various studies have shown that 
many survivors of child sexual abuse have at least some period of time in which they had incomplete or absent memories of their abuse, making it all the more difficult for victims to recall specifics of past incidents of sexual abuse (Herman \& Schatzow, 1987; Briere \& Conte, 1993; Loftus, Polonsky, \& Fullilove, 1994). Definitional difficulties regarding what constitutes child sexual abuse may not only make prevalence rates impossible to determine but may also skew the information regarding the population victimized by child sexual offenders. This means that the information available regarding victims of child sexual abuse may not be reflective of who are truly victims of CSA.

Victims of CSA

Despite the breadth of literature examining child sexual abuse, a prototypical victim typology has not been found. Despite research attempts to identify particular victim characteristics that may predict future victims and thus assist in the development of prevention programs, no particular characteristic group has been identified. Victims of CSA constitute all races and ethnic backgrounds, socioeconomic levels, educational levels and both genders. Most studies have found that females appear to be sexually abused at higher rates than males and that children in lower socio-economic levels tend to report sexual abuse at higher rates than children in higher socio-economic levels. However, factors such as socio-economic level do not appear to protect children from abuse (Salter, 1988). There are no statistically 
significant differences in rates of CSA by socio-economic status and commonly held beliefs regarding risks of CSA may not be accurate (Russell, 1986; Finkelhor \& Hotaling, 1984). Interestingly, although children of any age can be victims of CSA, the most vulnerable group appears to be children ages 8-12 years (Finkelhor \& Hotaling, 1984; Russell, 1983). Again, there needs to be caution when considering such research findings since most studies are retrospective and earlier onset abuse may be more difficult for research participants to recall. Such studies, however, do point to potential factors (e.g., gender, age) that may increase a child's risk of sexual abuse.

Parental absence and unavailability, however, appear to be one area of risk that has been shown to increase the probability of child sexual abuse (Finkelhor et al., 1986). Types of parental absence and unavailability that may increase the risk of CSA to a child include: living without a natural mother or father for any period of time during childhood (Finkelhor \& Hotaling, 1984; Russell, 1986), presence of a step-father (McCloskey \& Bailey, 2000), a disabled or ill parent (Finkelhor \& Hotaling, 1984; Herman \& Hirschman, 1981), a poor relationship with parents especially mothers (Landis, 1956; Finkelhor \& Hotaling, 1984), parental conflict (Gruber \& Jones, 1983), and having a non-biologically related father figure (Finkelhor, 1980; Gruber \& Jones, 1983). Although these cannot be names as causal factors for the occurrence of sexual abuse, information regarding these risk factors 
may be used to develop prevention programs or may assist to buffer potential impacts for children who suffer sexual abuse.

\section{Victim Impact}

In contrast to the paucity of literature exploring the causes of CSA, the effects of CSA have been studied extensively. Child sexual abuse has been found to have a significant impact on its victims, the victim's family, as well as the society atlarge. A wide range of interpersonal and psychological difficulties affect victims of CSA in both the short and the long term (Briere \& Elliott, 1994). Post-traumatic stress disorder (PTSD) represents a particularly salient short-term impact. Symptoms of PTSD include intense fear, helplessness and in children, disorganized or agitated behavior, persistent re-experiencing of the trauma, increased arousal including difficulty falling or staying asleep, irritability or outbursts of anger, difficulty concentrating, hyper-vigilance, or an exaggerated startle response (DSM, 2000). Other short-term consequences of CSA may include cognitive distortions of hopelessness, impaired trust, low self-esteem and self-blame (Briere \& Elliott, 1994).

Although short-term effects of child sexual abuse can certainly disrupt the day to day life of victims for a period of time following the abuse, short-term consequences of CSA may also persist to become long-term effects. Children who have been sexually abused may also experience depression, anxiety and physical symptoms such as stomachaches or headaches. Long-term effects of CSA may 
include an impaired sense of self, dissociation, substance abuse and addiction, suicide, indiscriminate sexual behavior, eating disorders and general interpersonal difficulties (Briere \& Elliott, 1994).

Several research studies have shown that long- term effects of CSA may be reflected in increased medical costs (Newman, Greenley, Sweeney, \& Van Dien, 1998; Walker, Unutzer, Rutter, Gelfand, Suanders, VonKorff, Koss \& Katon, 1999). Walker et al. (1999) found that adult victims of child sexual abuse had an increase in median annual health care costs of $\$ 245$ per year over those who reported no CSA histories. These researchers also found that CSA victims were more likely to make emergency department visits. Studies of this nature provide empirical evidence that CSA is not just an individual's malady but a pervasive problem that directly or indirectly impacts a large proportion of society.

Societal Impact

As previously mentioned, many questions have been raised regarding the costs associated with CSA. In addition to victim costs, the offender related financial burden has included but is not limited to: the pretrial investigation, the trial process, incarceration costs, offender specific treatment, community-based supervision following incarceration and community notification and supervision.

More than a decade ago Prentky and Burgess (1990) published a cost-benefit analysis examining the rehabilitation costs for child molesters. Prentky and Burgess 
investigated the cost-efficiency of treating adult sexual offenders at the Massachusetts Treatment Center. These researchers included only offenders with hands-on re-offenses, and excluded other "nuisance" offenses (e.g., voyeurism). The sexual recidivism rate of treated offenders was approximately $25 \%$ over five years, while rates for untreated offenders were approximately $40 \%$. Costs for incarceration alone for each offender was estimated at approximately $\$ 22,662$ per year. The cost of treatment and incarceration was estimated at $\$ 23,166$ per person. To determine the monetary costs of each new offense to society Prentky and Burgess added the expenses of investigation, apprehension, trial, incarceration and supervision to the victim related expenses such as medical exams, social services, witness services, and treatment. After all the expenses were totaled, one reoffense was estimated to cost $\$ 183,333$. After taking into consideration the recidivism rates, the researchers estimate that the original case plus one reoffense would cost $\$ 67,989$ more for offenders who have not been treated. Given that offense rates are typically considered an underestimate of the true incidences, the monetary costs to society would be considerably higher. These costs are, however, particularly astounding when one considers that the cost estimates are a decade old and that offense rates reflect an underestimate.

Research has also demonstrated other benefits of early intervention and offender treatment (Walker et al, 1999; Newman et al., 1998; Marshall, 1992). A 
recent study indicated that approximately $140,000(60 \%)$ of the sex offenders supervised by the correctional system are placed in the community and approximately $85 \%$ are ultimately mandated to treatment (McGrath, Cumming, Livingston \& Hoke, 2003). Although many if not most sex offenders are required to pay for their own treatment expenses at an average cost of $\$ 40-45$ per group session, many programs receive at least some public subsidy (Burton \& Smith-Darden, 2002). With many states expanding their definitions of sexual abuse and increasing their prosecution rates, expenses of this nature will increase the burden on an already strained economy and social service program funding. However, as suggested in the literature examining recidivism rates, high quality treatment of sexual offenders may help to lower reoffense rates and in turn reduce both human and financial costs to society (Prentky \& Burgess, 1990).

Finally, costs to society do not begin to address the impact on secondary victims of sexual assault. Secondary victims may include nuclear and extended family members, and friends of victims as well as offenders. Family members and friends may experience a broad range of emotional and stress related difficulties (Remer \& Furguson, 1998; Schonberg, 1992; Remer \& Elliott, 1988). Monetary costs due to time off work may be high as well. Parents and caregivers need to take their children to a myriad of medical, mental health and court appointments that are scheduled for both the victim and the offender. Offenders' families, particularly in 
the case of juvenile perpetrators may need to be present for evaluations, court appearances and treatment appointments. In some cases, parents, caregivers and family members may require their own involvement in the treatment process to foster recovery from the traumas secondary to sexual abuse (Remer \& Elliott, 1988). Often families require assistance to not only cope with the day to day events that require attention after an offense but also families are often left with many questions about what unique characteristic caused their loved one to sexually offend.

Researchers have looked at various aspects of offenders and offending and has led to theories about the etiology and pathology of sexual offending.

History of Research About Sex Offenders

Interest in studying sex offenders has expanded greatly over the last few decades. Prior to the 1970's though, there was a paucity of research examining sexual offenders. While studies examining the behavior of sexual offenders dates back to the early 1900 's, such studies were only published sporadically and often looked at extreme, incarcerated populations. Unfortunately, early efforts to understand this phenomenon led to a variety of misconceptions including the belief that victims were responsible for their own sexual abuse (Salter, 1988). Such victim blaming was so entrenched in the early literature that it continued through the 1970's and into the 1980's (Salter, 1988). 
Another popular misconception suggested that some offenses occurred “accidentally" (Landis, 1956). Such "accidental” offenses (e.g., exhibitionism) perpetuated victim blaming, particularly if the child did not immediately report the abuse. Still more disturbing was the fact that such "accidents" allowed offenders to avoid responsibility for their abusive behaviors. Additional misconceptions rooted in the early literature included the belief that offenders: are always men; are overly exposed to pornography and sexual behaviors as children; are not secure enough in their masculinity and therefore need to prove their manliness through abusive behaviors; and are immoral and brought up with sex as a strictly forbidden topic (Cohen, Garofalo, Boucher, \& Seghorn, 1971). Early perspectives on child sex abuse also suggested that it was not that harmful to the child victims due to reports of rather quick recoveries with few "permanently wrong attitudes" acquired (Landis, 1956). As a result of these long held misconceptions, a false sense of security has been instilled in the public suggesting that they can easily identify individuals who pose a risk to sexually abuse their children.

By portraying the sexual offender as someone overtly different than the rest of society, public fears could be allayed. False hopes also extended to intervention for sexual offenders. Unfortunately, early interventions such as psychosurgery (e.g., amygdalectomies) and castration were undertaken with the belief that the "cure" for sex offending had been discovered (Sadoff, 1975). Even today it is not unusual to 
overhear members of the public cry out for an accused sex offender to simply be castrated so that the problem "will be solved." This is despite the fact that research has demonstrated that castration alone may not stop offenders from continuing to abuse children (Kozol, 1971; Cooper, 1986).

Finally, a prevalent public misconception involves the belief that most offenders are "crazy" and therefore are not truly responsible for their offending behavior. In fact, less than $5 \%$ of all child molesters appear to be psychotic, and the only diagnosis made for sexual offenders with any consistency is antisocial personality disorder (Laws \& O'Donohue, 1997). In contrast to the many misconceptions that have been perpetrated; a number of theories have been posited based on the existing literature to enhance our understanding of sexual offending behavior.

\section{Characteristics of Juvenile Sex Offenders}

Although a great deal of attention has been directed to adult sex offenders, juvenile offenders constitute a significant proportion of sexual abuse perpetrators. Overall, juvenile offenders may account for as many as $50 \%$ of all child sexual abuse cases and $20 \%$ of all rapes (Barbaree, Marshall, \& Hudson, 1993). Moreover, as many as $50 \%$ of adult sex offenders have reported sexually deviant behavior beginning in adolescence (Becker, 1988; Ferhenbach, Smith, Monastersky \& Deisher, 1986; Marshall, Barbaree, \& Eccles, 1991). One study found that $56 \%$ of 
reported cases of child sexual abuse involved an offender under age 18 (Fehrenbach et al., 1986). Studies have also shown that what appear to be more minor offenses (e.g., voyeurism, exhibitionism) in adolescence may progress to more serious assaults in adulthood (Longo \& Groth, 1983).

The majority of adolescent sex offenders begin offending prior to the age of 15 , while these behaviors can also be present in children under the age of 12 (Araji, 1997). While a small percentage of juvenile sex offenders are female $(9.3 \%)$ the vast majority are males (English \& Ray, 1991). Several studies have found juvenile sexual offenders to be generally socially immature, to lack assertiveness skills, to prefer playing with younger children, to report deviant sexual fantasies and inappropriate sexual beliefs (Abel, Mittleman \& Becker, 1985). However, more recent studies have suggested that there may not be a "typical profile" for an adolescent sex offender (Hunter \& Becker, 1994; Levin \& Stava, 1987).

Despite evidence of the heterogeneity of juvenile sex offenders in many regards (e.g., age, abuse history) some studies have shown that juvenile sex offenders tend to fall into one of two categories: those who molest children and those who sexually offend against peers or adults (Barbaree, Hudson, \& Seto, 1993). Although there may be some cross-over in offending, these two types of juvenile perpetrators tend to adopt a different modus operandi (i.e., patterns of offending) based upon their relationship with the victim. In other words, child molesters tend to 
molest children either related to or well known to the offender while those who offend against peers or adults are more likely than molesters to offend against strangers or casual acquaintances (Barbaree et al, 1993). The vast majority of juvenile offenders in one study were either related to or otherwise knew their victims well (e.g., babysat the victim, friend of the family, etc., Fehrenbach et al., 1986). Rarely are strangers the victims of juvenile child molesters, but more likely strangers are victims of juvenile exhibitionists or voyeurs. Generally, juvenile sex offenders who molest children target stranger victims in less than $10 \%$ of offenses (Mathews, Hunter, \& Vuz, 1997). Although they primarily offend against children they know or are related to, juvenile offenders do use varied modus operandi and in fact juveniles use more modus operandi tactics than do adult offenders (Kaufman, Holmberg, Orts, McCrady, Rotzien, Daleiden, \& Hilliker, 1998).

Juvenile sex offenders have reported the use of threats and coercion in the commission of their crimes. Fehrenbach and his colleagues (Fehrenbach et al., 1986) found that the juvenile offenders used a weapon in $4 \%$ of the cases in their sample, used physical force in $33 \%$ of the cases, threatened physical force or the use of a weapon in $12 \%$ of the cases and used intimidation or bribery in $28 \%$ of the cases. Only about $6 \%$ of the cases involved the use of alcohol or drugs by the victim or offender at the time of the offense (Fehrenbach et at., 1986). Although very little research has been completed regarding the modus operandi of juvenile sex offenders, 
developmental factors as well as personal histories may be an influence in a juvenile's modus operandi. To better understand possible influences on juvenile offenders' use of various modus operandi it is important to know more about the general histories of juvenile offenders.

Juvenile sex offenders have reported a higher incidence of their own child maltreatment than found in the general population. While approximately $10-20 \%$ of males in the general population report having been sexually abused, much higher rates of male sex offenders report a history of sexual abuse (Finkelhor, et. al., 1986; Hunter, Childers, Gerald, \& Esmaili, 1990). Dhawan and Marshall (1996) have found that out of a small sample of juvenile sexual offenders (i.e., including 29 rapists, 16 child molesters and 20 non-sexual offenders), $62 \%$ of the rapists reported a history of their own sexual abuse, $50 \%$ of the child molesters and $20 \%$ of the nonsex offenders report a history of abuse. Seghorn, Prentky, and Boucher (1987) found high rates of physical abuse, neglect and other family of origin difficulties (e.g., criminal histories and alcohol abuse) in a sample of incarcerated sexual offenders.

Of course, not all abused children become child abusers, however, some etiological factors may be more likely to suggest who may be at greater risk to go on to become a sexual offender. One such factor may be related to the quality of a child's family of origin. Various studies have found sexual offenders' family of origin to be characterized by a variety of difficulties that include substance abuse, 
poor interpersonal interactions, and criminal histories (Seghorn et al., 1987).

Findings of this nature may enhance the prediction of the factors that lead abused children to sexually offend. Perhaps such information will also assist in understanding the mechanisms that produce adult sexual offenders.

\section{Characteristics of Adult Sex Offenders}

Many attempts have been made to identify the "typical" adult sex offender. As with juvenile offenders, adult sexual offenders are a heterogeneous group. Like their juvenile counterparts, adult offenders are represented in all locations in society. Adult offenders are also represented in all racial and ethnic backgrounds, all socioeconomic strata, all education levels and can be either male or female although the majority of offenders are male. In fact, Herman (1990) stated that, "the most striking characteristic of sex offenders, from a diagnostic standpoint, is their apparent normality." Contrary to previous beliefs that child molesters were most likely strangers who lurked in bushes just waiting for an unsuspecting child to wander by, the vast majority of sex offenders are either related to or well known by their child victims. Halliday (1985) found that $13 \%$ of offenses were perpetrated by strangers while Russell (1983) placed the figure at $11 \%$. Other studies have placed the percentage of offenses perpetrated by strangers at higher levels, however, those findings appear to be somewhat skewed since families are less likely to report abuse by other family members or people within their immediate social circle (Groth \& 
Birnbaum, 1978). One early study found that nearly $50 \%$ of molestations occur when the perpetrator is supposed to be babysitting the child (Fehrenbach et al., 1986). Although this number appears to be quite high, Fehrenbach and his colleagues' definition of babysitting also included father figures who watched children for short periods of time while their mother was out of the house (van Dam, 2001). Given that so many perpetrators of sexual abuse are well known to the victim and the family, it is surprising that so little research attention has been devoted to the identification of etiological factors that could guide effective interventions. 


\section{Theories of Child Sexual Abuse}

Many theories have been postulated to explain sexual assault. Although social learning theory will be thoroughly explored later, it is important to briefly explore other theories to explain the sexual abuse of children.

One theory of sexual assault comes from a feminist perspective. This theory states that sexual assault is primarily a serious issue in our society because of the imbalance of power between men and women or others with less control in the decisions of our society (e.g., children). Since sexual abuse is most often perpetrated by males and the victims are believed to be more often females, the theory is that sexual assault is a perpetuation of the power and control that men hold over women and those less powerful than men in Western societies. This theory would also assist to explain the sexual abuse of boys as well since they are also less powerful and have less control than adult men in Western society. Cross-cultural studies have supported higher incidences of rape in male dominated societies (Herman, 1990). According to feminist theory of sexual abuse, although male sexual victimization of other males is most often preceded by a traumatic event (e.g., sexual abuse by an older male), normal socialization in a male dominated society is enough to produce male sexual aggression. Prevention of sexual abuse according to this model in some ways mirrors the prevention discussed for social learning. Socialization of children and the society as a whole is the best intervention for this problem and the best prevention for sexual 
abuse in the future. When society treats all members with the same respect and distributes the power and control evenly sexual assault will no longer be a byproduct of an imbalance in societal power.

Another theory of sexual abuse is the psychoanalytic theory as explained by Malmquist (1972). According to this explanation, sexual abuse is a disorder of the malfunctioning superego and an individual dominated by the id. Basically this theory states that the sexual offender is developmentally arrested in their sexual development. Rather than developing more age appropriate sexual expressions, this individual maintains the sexual interactions of their childhood. This individual will continue to interact sexually with younger children rather than risk the unknown and more threatening interactions with peers and adults. Instead of developing other neuroses, this individual continues the expressions of infantile sexual fantasies which have been accepted by the ego.

One theory that is often incorporated to some degree into other theories of sexual offending is the cognitive theory. This theory explores the cognitive distortions of sexual offenders and how those distortions are used to support assaultive behaviors (Abel, Osborn, \& Twigg, 1993). Such cognitive distortions allow offenders to justify or excuse the sexually assaultive behaviors. Offenders may also combine these cognitive distortions with other offender characteristics such as poor impulse control, low self-esteem, feelings of powerlessness and emptiness, poor 
coping and problem-solving skills (Abel et al., 1993). It is the combination of these offender characteristics with the cognitive distortions that allow offenders to sexually abuse without considering the damage to the victim.

\section{Learning Theories of Sexual Offending}

Although many theories have been explored to assist in the explanation of sexual offending, no one theory has been found to fully explain the development and maintenance of sexually deviant behavior. As technology advances and more is learned about brain functioning and physiological processes there may be more room for biological explanations of sexually deviant behavior. At this time, however, there is little conclusive evidence that sexually deviant behaviors have their origins in organic brain damage or other biological maladies. Instead, a great deal of research has focused on and been supported by the notion that environmental influences may explain a great deal of the sexual offending. Specifically, various forms of learning have been explored as potential etiological explanations for sexual offending.

Studies have demonstrated that sex offenders, in general, report higher rates of their own maltreatment than members of the general population. Moreover, studies of child maltreatment have shown that the effects of child neglect and abuse impact a child's early development and life course. Children who are not provided with stable, secure and affectionate models at home may seek those qualities in other settings and from any adult offering comfort. As a consequence, children growing up 
in deprived environments (e.g., neglectful or abusive homes) may be more susceptible to inappropriate advances of adults around them. Further, children from such environments may learn poor coping skills and turn to other self-soothing means (i.e., excessive sexual behaviors, exercises of power and control, masturbation, etc.) to avoid dealing with the real problems in their lives (Marshall \& Marshall, 2000). It may be assumed from the large numbers of children abused in our society (relative to the small number of sexual offenders) that the majority of children from impoverished environments do not acquire deviant sexual interests. However, Marshall and Marshall (2000) theorize that it is this early detrimental environment that may explain the etiology of the development of deviant sexual fantasies and behaviors. Such fantasies and behaviors may be acquired and maintained through conditioning and modeling of inappropriate behaviors (Marshall \& Marshall, 2000; Laws \& Marshall, 1990).

Learning theories have been suggested as possible explanations for the development and maintenance of deviant behaviors (Laws \& Marshall, 1990). The basic premise underlying learning theory suggests that sexual offenders acquire sexually deviant preferences the same way that they acquire many other behaviors, through a conditioning process. Learning theories include classical conditioning, operant conditioning, and social learning. 
The classical conditioning theory of learning appears important for understanding the development of particular offending components such as deviant sexual arousal while operant conditioning and social learning may contribute to the development and maintenance of particular offending components such as deviant sexual fantasies. To better understand Laws and Marshall's (1990) assertion, a brief review of classical conditioning may be helpful. Generally, classical conditioning theory states that if an unconditioned stimulus (e.g., sexual fantasy subject) is paired with a naturally occurring or unconditioned physiological response (e.g., fear response, sexual arousal response), over time the stimuli will produce that unconditioned response. The formerly neutral stimulus becomes what is known as a "conditioned stimulus" with a conditioned behavioral response. Laws and Marshall (1990) point out that in order for this theory to be accepted, it must be assumed that human sexual arousal is an unconditioned response. Assuming that this is the case, the pairing of particular stimuli (i.e., appropriate or inappropriate) with sexual arousal will cause the stimuli to evoke a response of sexual arousal. In other words, this theory postulates that if deviant sexual fantasies are repeatedly paired with sexual arousal through masturbation, a strong desire to engage in those fantasized behaviors will develop. Additionally, other studies have also found that no reward at all also results in the continuation of the behavior (Pfiffner \& O'Leary, 1987). These findings may be important to understand the acquisition of sexually deviant 
behaviors because although there may be no reward (e.g., orgasm) there is also no punishment to extinguish the behavior (e.g., getting caught and the social/ legal consequences).

One clear difference between the acquisition of deviant sexual behaviors and the acquisition of other behaviors is that with the development of sexual behavior there is generally no pairing of arbitrary stimuli (e.g., surrounding items such as a bedroom dresser) with arbitrary behavior, but instead these pairings are highly specified (Laws \& Marshall, 1990). In other words, there are few other stimuli that will detract from the strength of this paired relationship. For example, a teenage male who has been socialized to be sexually attracted to females has fantasies of age appropriate females. However, for one reason or another (e.g., poor social skills) he may find it difficult to become intimate with a female peer. As his interests increase in sexuality and after continued frustration with peers, he may take advantage of a home situation (e.g., poor caregiver supervision) that lends itself to abusive involvement with a younger male or female child. His arousal becomes associated with the look and feel of the younger child's body. See Figure 1 for classical conditioning processes and sexual offending. 
Figure 1. Classical Conditioning and Sexually Offending.

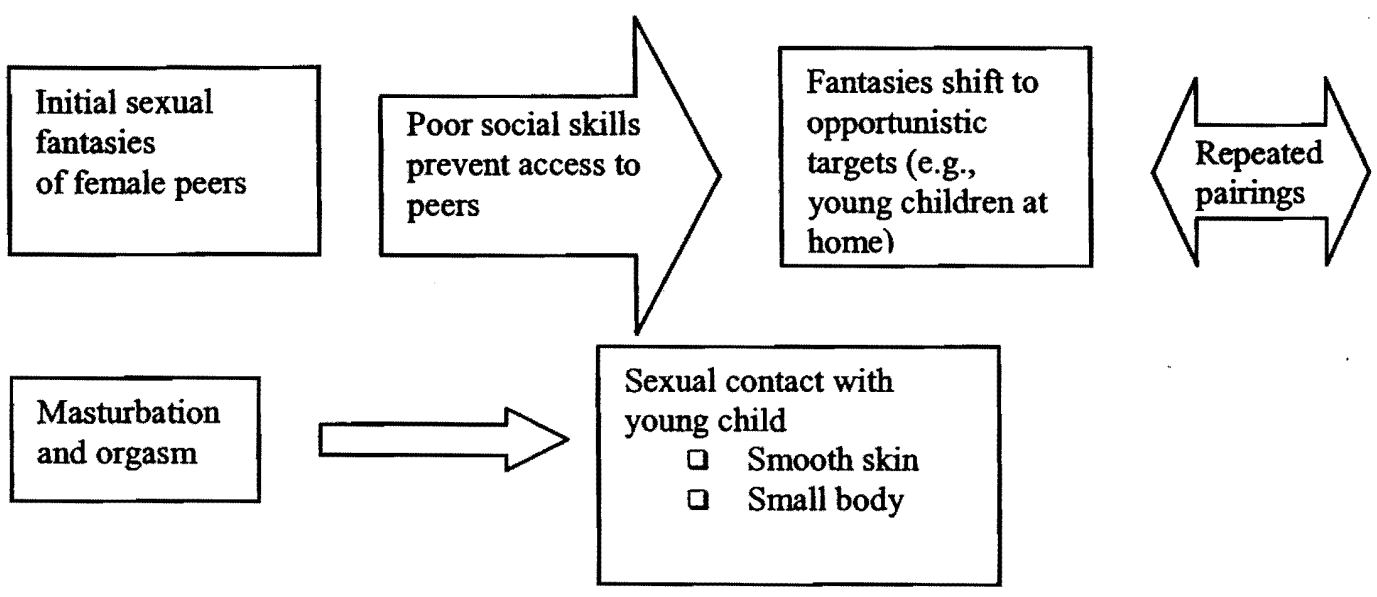

In a related, but slightly different process, operant conditioning is also believed to influence the acquisition of sexually deviant interests and behaviors. Operant conditioning is the process by which a behavior is followed closely in time by a consequence (i.e., reward or punishment) and the behavior increases or decreases in the future based on the valence of the consequence (i.e., positive or negative). For example, operant theory would explain the increase in a teen's sexual arousal to fantasies involving young children by suggesting that these fantasies are reinforced by the sexual gratification that the teen receives from sexual orgasm which follows masturbation while thinking about young children. Whereas a teen's initial arousal may develop based on the classical conditioning paradigm previously described, it may be strengthened and maintained through an operant reinforcement process. See figure 2 for operant conditioning and sexual offending. 
Figure 2. Operant Conditioning and Sexual Offending.

\begin{tabular}{|c|c|c|c|}
\hline $\begin{array}{l}\text { Arousal to } \\
\text { young } \\
\text { children } \\
\text { (developed } \\
\text { through } \\
\text { classical }\end{array}$ & $\begin{array}{l}\text { Fantasies } \\
\text { of sexual } \\
\text { contact } \\
\text { with young } \\
\text { children }\end{array}$ & $\begin{array}{l}\text { Followed by } \\
\text { reinforcement } \\
\text { of } \\
\text { masturbation } \\
\text { and orgasm } \\
\text { (reward) }\end{array}$ & $\begin{array}{l}\text { Increased } \\
\text { arousal } \\
\text { to } \\
\text { fantasies } \\
\text { of young } \\
\text { children }\end{array}$ \\
\hline
\end{tabular}

Operant conditioning may also explain the shift away from age appropriate sexual fantasies for some teens. For example, a teen who's initial fantasies about peer-females are followed by social rejection may show a reduction in such fantasies. Figure 3. Arousal conditioning.

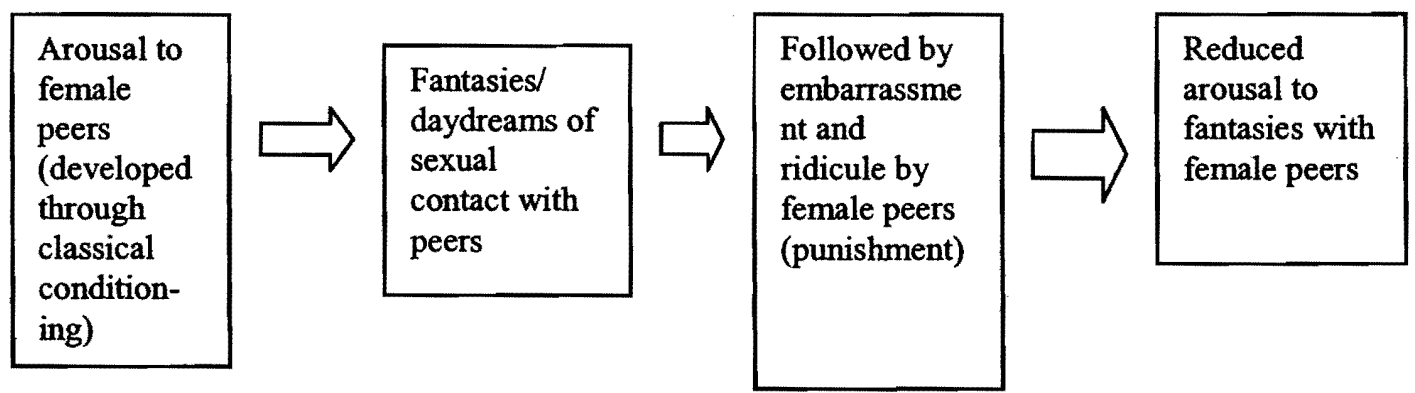

This basic understanding of conditioned responses to sexual arousal assists in our understanding of how more complex processes such as social learning principles may explain sexual offending. In general, sexual behavior is also social behavior. With the exception of masturbation, sexual behavior requires the participation of another person. Social learning theory may be understood as a more complex form of 
operant conditioning. Social learning theory states that people apply cognitive processes to the consequences they encounter (or they observe others encounter) rather than simply reacting to those consequences (Bower, Bootzin, \& Zajonc, 1987). In other words, people receive reinforcement or punishment from others around them either directly or vicariously and these consequences influence future behavior. According to learning models, reinforcing consequences will result in the individual increasing a particular behavior. If an individual perceives a response by someone around him to be positive or reinforcing (e.g., praise), the individual will continue to engage in a particular behavior. Punishing consequences on the other hand will result in a decrease in behaviors. For example, if a teenage boy approaches a peer female and asks her out on a date and the female rebukes his efforts or ridicules him, the male may cognitively generalize this reaction and would not approach any other peer females for dating purposes. He may feel hurt or rejected and may not want to experience these feelings so he decides not to interact with other female peers. However, if the female reciprocates his interest or does not generally respond, the male may find this reinforcing or not punishing and will continue to either pursue this particular female or generalize and pursue other peer females for dating purposes. He may think about the positive reasons that the girl reciprocated his attention or if the girl simply did nothing he may think of reasons that she did not 
respond but does not consider them to be personal (e.g., she had too much homework or was otherwise too busy).

There are three specific processes that contribute to the acquisition of social behaviors including sexual behavior: participant modeling, vicarious learning, and symbolic modeling (Bandura, 1973). Participant modeling is the process by which a person learns a behavior by being directly involved in a behavior with others and replicates that behavior at a later time. In the case of deviant sexual behavior participant modeling may occur when a child is sexually abused by an adult, and the child later sexually abuses a much younger child in the same manner that he was abused. The child was directly involved in the initial sexual abuse and learned those behaviors from direct experience.

Although participant modeling may explain the etiology of some sex offenders, research has indicated that participant modeling is not the etiological explanation for all sexual offending. Many adult sexual offenders attempt to explain their behavior based upon the participant modeling theory of social learning. However, studies have shown that although sex offenders may experience a higher rate of sexual abuse as a child when compared to the general population, the majority of sexual offenders have not actually been sexually abused as children (Hindman \& Peters, 2001). In Hindman and Peters' (2001) study adult and juvenile sex offenders were asked if they had been sexually abused as a child. Offenders reported very high 
rates of child sexual abuse ( $80 \%$ for adults and $60 \%$ for juveniles). The offenders then submitted to polygraph examinations to determine how many had truly been abused. The polygraph results indicated that adult offenders had actually been sexually abused about $30 \%$ of the time, while juvenile offenders had been abused about $40 \%$ of the time. Though well above prevalence rates estimated for the general population, this study reveals high rates of offender over-reporting. Although participant modeling may certainly have some influence on later sexually deviant behaviors (e.g., sexually abusing someone in the same manner in which the offender had been previously abused), participant modeling alone does not seem to explain sexual offending.

Vicarious learning is the process by which a non-participant observes (but is not directly involved) someone else's behavior and later reproduces that behavior. An example of vicarious learning is reflected in a person who either watches sexual abuse occur in person or through some type of media (e.g., pornography, sexually explicit videos or movies), experiences sexual arousal, and later re-enacts those behaviors with an inappropriate partner (i.e., much younger, unwilling, coerced). Again, many adult sex offenders have claimed that exposure to large amounts of explicit pornography as young children explains the etiology of their sexual offending. However, research studies have suggested that sexual offenders are not typically exposed to an overabundance of pornography as children and in fact, many 
report less exposure than control participants who had not sexually offended (Goldstein \& Kant, 1973; Cook, Fosen, \& Pacht, 1971). In addition, Becker and Stein (1991) found that sexually explicit material did not play role in the majority of sexual offenses. However, more recent studies have shown that there may be a relationship between early exposure to pornography and sexual offending (Tabacoff, 2002). Other recent studies have also concluded that exposure to pornography may only influence those with a predisposition to sexually offend (Seto, Maric, \& Barbaree, 2001). Consequently, vicarious learning may explain some but not all offenders' behaviors.

Symbolic modeling is the process by which behavior and the ensuing consequences (negative or positive) are developed and enhanced through fantasy (Laws \& Marshall, 1990). In sexual offending this process may be exemplified by someone who masturbates to deviant fantasies. According to this theory any kind of exposure to deviant stimuli, whether through personal experience or media presentation, is enough to supply the information requested to formulate deviant fantasies. Although there are varying definitions of the term 'deviant' just as there are varying definitions of child sexual abuse across research studies, the term deviant for the purpose of this project will include those sexual behaviors considered to be socially unacceptable (or not openly endorsed by the mainstream public) and most often illegal. Although this continues to incorporate a wide variety of sexual 
behaviors, there are generally more or less acceptable sexual behaviors, with those less acceptable behaviors often prohibited by law.

In the process of symbolic modeling, scenarios may be created and enhanced by the offender through fantasy elaboration along with masturbatory reinforcement and enacted with whomever the offender has access. In many cases this may be a younger family member due to social inadequacies that do not allow appropriate peer interaction to develop. While symbolic modeling may not necessarily be implicated in the development of sexual offending, it may explain one component of the maintenance process.

In summary, sexual offending is a complex behavior and no single theory has been found to adequately explain its development and maintenance. While certain theories have been applied to explain particular offending components such as deviant sexual arousal, researchers continue to examine other possible etiological factors in the development and maintenance of sexual offending. Perhaps the answer to this dilemma lies not in any one theory but a combination of various theories to explain the multiple components of sexual offending. Whereas classical conditioning may explain the development of deviant sexual arousal, operant conditioning may explain the development and maintenance of deviant sexual fantasies. Further, social learning theory may offer a possible avenue for the acquisition of deviant sexual behaviors due to the social nature of human sexual behavior. No matter how sexual 
offending behaviors develop, it is clear that deviant fantasies are at least one component involved in the development and maintenance of sexual offending behavior (Hunter, Goodwin, \& Becker, 1994; Looman, 1995; Butz \& Spaccarelli, 1999; Pithers, Beal, Armstrong, \& Petty, 1989). In order to better understand the role of deviant fantasies in sexually offending, a general understanding of fantasies in human sexuality is necessary. 


\section{Fantasies}

Webster's dictionary defines fantasy as “imagination or fancy" (Neufeldt \& Sparks, 1995). In a seminal review, Leitenberg and Henning (1995) bring a more focused definition, "an act of the imagination, a thought that is not simply an orienting response to external stimuli or immediately directed at solving a problem or working on a task" which may include an elaborate story, or a fleeting thought that is realistic or imaginative. These researchers go on to define a sexual fantasy as "almost any mental imagery that is sexually arousing or erotic to the individual" (pg. 470). The reasons for developing sexual fantasies are another debate. Freud believed that sexual fantasies were symptomatic of sexual dissatisfaction, an infantile reaction to unresolved wishes and wants. These sexual fantasies are used to compensate for an unsatisfactory experience with sex in their lives (Freud, 1962). Meanwhile, Singer believed the opposite; instead believing that sexual fantasies were meant to symbolize healthy sexuality through enhancement of sexual arousal and enjoyment (Singer, 1966).

Studies of young children's (under age 5) fantasies have revealed that very few, if any, fantasies contained sexual content (Ames, 1966). Fantasies were determined from imaginative stories told by the children. As the age of the child increases, the sexual content of their fantasy life also increases (Sutton-Smith \& Abrams, 1978). Due to the difficulty associated with collecting this information in 
children, most information regarding the age of onset for sexual fantasies is retrospective. A 1991 study by Gold and Gold found that the mean age of onset for sexual fantasies for men was 11.5 years.

Sexual fantasy content has also been studied within the general population. Hunt (1974) found that there were five common sexual fantasies for both men and women including: intercourse with a loved one, intercourse with a stranger, doing things that you would never do sexually in reality, multiple sex partners of the opposite sex at the same time, and sexual contact involving force. One caution must be taken with older studies of sexual fantasy focusing on heterosexual themes (e.g., multiple sex partners of opposite sex) rather than using non-biased vocabulary (e.g., multiple sex partners). Such heterosexually biased themes may overlook many sexual fantasy themes that may be quite common in the general population. Other studies have shown that oral-genital contact, sex with a new partner, sex with a celebrity and replay of prior sexual experiences were also very common fantasy themes (Sue, 1979; Shanor, 1978; Shanor 1977; Wilson \& Lang, 1981). Although the most common sexual fantasies are those involving a past or imagined sexual partner, forced sexual experiences are often a very common sexual fantasy (Leitenberg \& Henning, 1995). In fact, one study found that $39 \%$ of men and $25 \%$ of women fantasize about forcing someone into sexual activities (Arndt Foehl, \& Good, 1985). In another sample of only men, $54 \%$ had fantasies of forcing women into 
sexual activities (Grendlinger \& Byrne, 1987). Although it is certainly not uncommon for the general population to experience sexual fantasies involving deviant behavior (e.g., forcing someone to engage in sexual activity), it is helpful to understand the development of fantasies in general to better understand the generation and maintenance of such deviant fantasies.

\section{Development of Sexual Fantasies}

With a better understanding of the themes that prevail in the sexual fantasies of Americans, the next step may be to explore the etiology of those themes, most specifically where sexual fantasies originate. Several theories explain why people develop particular sexual fantasy preferences. One explanation is based on a simple conditioning model. Past sexual experience coupled with orgasm is quite rewarding and when this stimulus is imagined at a later time and coupled with masturbatory behaviors, the stimuli is reinforced as sexually arousing (Leitenberg \& Henning, 1995). The pairing of the sexual stimuli with sexual arousal reinforces fantasies with sexual content. Despite whether the origination of fantasies rests in real life experiences or in the imagination, it is the reinforcement of the sexual arousal that allows the fantasy to maintain its potency and persist. Further, unlike real experiences, fantasies may be modified by an individual to be even more arousing depending on the individual's personal preference, including deviant preferences. 
Additional explanations for the development of deviant sexual fantasies include such theories as participant modeling, vicarious learning, symbolic modeling, and psychoanalytic theories of wish fulfillment. Many of these themes have been explained earlier in this paper. These theories may also explain the development of deviant and non-deviant fantasies.

\section{Deviant Fantasies and Sexual Offending}

Although we now know that many people have fantasies about sexual things that they do not act upon in real life (e.g., rape fantasies appear to be more prevalent than actual rapes reported), it is still not known why some people act on those deviant fantasies while others do not (Leitenberg \& Henning, 1995). Rokach (1990) found that $2.6 \%$ of college men and $1.2 \%$ of college women reported a sexual fantasy about children. Sexually violent fantasies were not uncommon in a general sample of nearly 100 men, with $33 \%$ reporting fantasies of rape, $39 \%$ fantasizing about tying a woman up and $61.7 \%$ fantasizing about "initiating" a young girl. Additionally, a 1989 study by Briere and Runtz found that out of 193 college males, $21 \%$ reported some attraction to children with $9 \%$ having some fantasies that involved children, and 7\% reporting some likelihood of having sex with children. The definition of a child (e.g., age) was not provided to the research participants.

Since research suggests that there is a small percentage of the population who admit to deviant fantasies, including sex with children and the use of force to 
sexually offend, the proportion of the population that act on such fantasies is obviously very small. Research has also demonstrated that people who report deviant sexual fantasies (e.g., rape) were more likely to use force or endorse rape supportive attitudes and were more likely to physiologically display sexual arousal to sexually coercive stimuli (Plaud \& Bigwood, 1997; Butz \& Spaccarelli, 1999).

Research with juvenile sex offenders indicates that those who have used force to sexually offend are more likely to report assault related fantasies, predatory behaviors, greater levels of deviant sexual interest and a greater number of victims (Butz \& Spaccarelli, 1999). Abel, Becker, Mittleman, Cunningham-Rathner, Rouleau and Murphy (1987) found that more than $40 \%$ of non-familial child molesters reported the development of deviant sexual fantasies prior to sexually offending. While this does not necessarily explain deviant fantasies as an etiological factor in all sexual offending, studies have shown that deviant sexual fantasies may often be precursors to further sexual offending (Pithers, et al., 1989).

Despite variations in offender subgroups, Marshall et al. (1991) found that $22 \%$ of the adult offenders experienced deviant fantasies prior to their first sexual offense. Other studies have examined the mood states of offenders and their corresponding sexual fantasies. These studies have reported that deviant and masturbatory fantasies were associated with negative mood (e.g., depression) suggesting that deviant fantasies may serve as an inappropriate coping mechanism 
(McKibben, Proulx, \& Lusignan, 1994; Proulx, McKibben, \& Lusignan, 1996;

Looman, 1995). Although the number of participants in the study was small $(\mathrm{N}=21$

child molesters, $\mathrm{N}=19$ rapists), $61 \%$ of child molesters and $7.7 \%$ of rapists in Looman's study (1995) reported deviant sexual urges or fantasies. Looman found that $53.9 \%$ of offenders who reported no deviant fantasies used physical coercion. Those offenders who reported no deviant fantasies physically injured their victims $53.8 \%$ of the time, while victims of offenders with deviant fantasies had no injuries (Looman, 1995).

Such findings indicate that there may be a relationship between deviant sexual fantasies and the use of physical coercion to sexually offend. However, the relationship between deviant fantasies and the use of physical aggression may be mediated by some other factor since about half the offenders reported deviant fantasies in association with physical coercion and about half did not. It should be noted that Looman (1995), as well as Proulx and his colleagues (1996) did not find a relationship for affective states and deviant sexual fantasies for same sex pedophiles. Deviant fantasies for same sex pedophiles appear to be related directly to sexual desires. Interestingly enough, Looman (1995) found that the same sex pedophiles were the most likely offenders to report current deviant fantasies and that these offenders were less likely to physically injure their victims. 
Some findings for juvenile offenders, however, have differed from findings regarding adult sexual offenders. One study found that the majority of juvenile offenders reported engagement of deviant sexual fantasies prior to offending (Hunter, et al., 1994). Although this is in contrast to Marshall et al.'s study (1991) of adult offenders, such contrary findings may illuminate possible differences in etiological factors as well as the modus operandi between adult and juvenile sexual offenders. Certainly more research is needed to better understand the role of deviant fantasies in the modus operandi, including the use of physical force, of sexual offending for both juvenile and adult sexual offenders. A better understanding of offenders' modus operandi may assist in the understanding of why about half of offenders report deviant sexual fantasies in conjunction with the use of physical force to offend and why other offenders do not report such ways of offending. 


\section{Violence and Sexual Offending}

Violence, or physical aggression, may also be explained by learning theory. Like sexual offending, more general violence may be a learned interpersonal response. Children begin to learn at a very early age that there are certain times and places that aggressive behaviors are allowed (Bower, et al., 1987). For example, aggressive behaviors may not only be allowed, but encouraged in situations such as team sports. However, in most day-to-day interactions aggression is not considered appropriate. From about the age of 2 or 3 years children begin to show aggressive behaviors through tantrums, hitting or throwing toys. Parents may begin to intervene at this age to teach the child that behaviors of this nature are inappropriate. However, from social learning theory, we know that children often learn behaviors through modeling the behaviors of adults around them. Therefore, even if a parent is instructing a child to not be aggressive to others, if the child is exposed to aggressive or violent behaviors in their environment, the child will often continue to engage in aggressive acts. In other words, much like sexual offending, violence may be learned through participant observation or vicarious learning. Findings also suggest that a child who displays more aggressive behaviors will go on to be a more aggressive adolescent and adult (Bushman \& Huesmann, 2001).

Many studies have demonstrated that exposure to violence through various forms of media may increase a child's propensity toward violence (Bushman \& 
Huesmann, 2001). A 1994 meta-analysis by Paik and Comstock examined the link between violence and the media to support the assertion that television violence correlates with three types of behavior: aggressive behavior, violent criminal behavior and non-violent criminal behavior. Arousal resulting from watching violent television programs has been shown to transfer to real behavior in other studies (Zillman, 1971; Geen \& O’Neal, 1969). Violence may also be normalized by television programming due to its over-representation relative to the reality of the amount of violence that occurs in our society (Oliver, 1994). This normalization not only cognitively desensitizes an individual to violence but it may also portray violence as more socially acceptable since it occurs so frequently on television (Bushman \& Huesmann, 2001).

Often children are also exposed to a combination of violence and sexually explicit content in the media. In some cases, the media has directly modeled sexually aggressive behavior toward women, rape, and even sexual murder (i.e., particularly when music videos are included). One particular study found that the pairing of sex and violence occurs in equal numbers of films rated "R," "X," and "XXX" (Yang \& Linz, 1990). Although research does not suggest that media violence is the direct cause of aggression in children, research does suggest that media violence has a very important influence on aggression in children (Singer \& Singer, 2001). 
Some studies, in particular, have found a relationship between exposure to violence through domestic violence and later physical aggression in interpersonal relationships including sexual offending. Jaffe, Suderman and Reitzel (1992) reviewed numerous studies demonstrating that children who observe domestic violence are much more likely to engage in a violent relationship than children who were not exposed to domestic violence. This study demonstrated that male adolescents who were exposed to adults in the home who used some physical force toward one another (30\%) used force in their own dating relationships more often than male adolescents $(7.2 \%)$ who had not been exposed to violence in the home (Jaffe et al., 1992). These authors also found that it was not simply exposure to violence toward women at home that influenced future behavior, but also exposure to violence on television, in movies, and in other forms of media. Media exposure as well as socio-cultural expectations encourage young males to establish inappropriate, if not frankly aggressive, sexual fantasies that for some, not only translates into increased sexual behaviors, but into sexual offending as well. 


\section{Violence and Fantasies}

A paucity of literature directly addresses the connection between violence and fantasies in sexual offending. From Leitenberg and Henning's (1995) review in this area we know that it is not uncommon for the general population, as well as sexual offenders, to engage in fantasies of violence. However, most people do not choose to act on those fantasies. Studies examining offenders' use of physical force or threats of physical force have found differing results depending on type of anger measured (e.g., temperament, reaction) against type of aggression (e.g., verbal, physical) utilized (Smallbone \& Milne, 2000). Basically, Smallbone and Milne (2000) found that those offenders who used verbal threats of death were more likely to have higher scores for such traits as directing anger outward and having lower levels of anger control. It appeared that those offenders who used physical aggression to offend used this method instrumentally because there was no association between type of anger and aggression. Some results have found a large number of sex offenders who have used physical force as part of their offense while other studies have found much smaller proportions of offenders who used force. Although the literature has explored fantasies independently, primarily for content, and the literature has somewhat extensively explored sexual violence, little has been done to establish a relationship between particular fantasies and patterns of offending 
(i.e., modus operandi). Even less research is available to compare the differences in violent modus operandi and fantasies between adult and juvenile sexual offenders.

It is anticipated that additional knowledge regarding potential relationships between fantasies and behaviors will assist in assessing accused and convicted sexual offenders for such clinical concerns as types of offenses previously committed and the possibility of offense reinforcement through fantasy elaboration. In addition, a better understanding regarding the similarities and differences of adult and juvenile sexual offenders may assist in the development of effective treatment interventions. More effective treatment will diminish recidivism rates and in turn decrease the number of victims. Additional information regarding the relationship between fantasy and violence for each group may indicate different types of treatment that may be more effective with different groups of offenders. For example, a strong relationship between types of fantasies utilized and types of violence used to offend may indicate a fantasy restructuring component of treatment. 


\section{The Current Study}

This study investigates the relationship between offenders' sexual fantasies and their use or threats of physical force directed toward child victims. It is also designed to examine the similarities and differences between adult and adolescent sexual offenders on these dimensions. While studies are beginning to show distinct differences between adult and juvenile sexual offenders in a variety of areas, the literature does not include an exploration of the relationship between sexual fantasies and offenders' use or threats of physical force. Nor have adult and juvenile offenders been compared on this dimension. These research hypotheses focus on the use or threats of physical force to offend, on offenders' reports of types and frequencies of fantasies, as well as differences between adult and juvenile sexual offenders in those areas.

Hypotheses

1. Adult sex offenders report a greater frequency of deviant sexual fantasies than juvenile sex offenders.

2. Juvenile sex offenders report a greater frequency of violent sexual offending behavior than adult sexual offenders.

3. There is a relationship between the use or threat of physical violence to sexually offend and deviant sexual fantasies. 
Adult and Juvenile Sexual Offenders 44

\section{Method}

The current study is part of two larger studies conducted by Dr. Keith

Kaufman. The National Institute of Mental Health (NIMH) funded a study in 1993 to examine adult sex offenders' modus operandi. The purpose of that study was to look at the methods adult sex offenders used to gain access to victims, commit their offenses and then keep the child from reporting the offenses. Dr. Kaufman consulted with the Safer Society Program, a national clearinghouse and referral service for adult and adolescent sexual offenders seeking treatment, to identify only those programs offering high-quality treatment. Only those programs recommended by the Safer Society Program were included in his study. Programs offering high-quality treatment were selected to reduce minimization and denial in questionnaire responses as well as to allow the participants access to mental health professionals should they experience any adverse effects from study participation. Approximately 874 adults participated from correctional facilities and outpatient programs in seven states: Minnesota, New York, Ohio, Oregon, South Carolina, Texas, and Washington. These participants ranged in age from 18 to 76 with a mean age of 38 years. Human subject approval was originally granted through Ohio State University and has been continued through Portland State University. Continuation for this project through Portland State University has most recently been approved through April 2003. 
A second study was conducted by Dr. Kaufman and funded through the Office of Juvenile Justice and Delinquency Prevention (OJJDP). The purpose of that study was to examine the modus operandi of juvenile sexual offenders. Again only programs identified through the Safer Society Program were contacted for participation to ensure high quality treatment was provided to participants. Approximately 507 juveniles participated from incarceration facilities and outpatient programs in six states: Minnesota, Ohio, Oregon, South Carolina, Texas, and Washington.

For both the NIMH study and the OJJDP study participants who could not read at a sixth grade reading level or whose intellectual abilities were too low to comprehend the questionnaires were excluded from the study. The numbers of excluded participants are unknown due to the initial screening process by the correctional institutions. Generally, participation in the study was reported by correctional personnel as high among the population of sexual offenders in each institution.

\section{Participants}

Participants for this study are comprised of a sub-sample from the larger NIMH and OJJDP studies. Two sub-populations were comprised of 114 juveniles and 114 adults. Participants in the sub-sample from the OJJDP study ranged in age from 13 to 20 with an average age of 15.98 years. Their age at the first sexual 
offense ranged from 5 to 17 years with an average age of 11.26 years. The number of victims for the juvenile sub-sample ranged from 1 to 33 with an average of 4.37. The sub-sample consisted of primarily Caucasian participants (61.4\%) while AfricanAmerican, Hispanic and Native American populations were well represented $(25.4 \%$, $10.5 \%$ and $14.9 \%$ respectively). The sub-sample from the NIMH study ranged in age from 21-76 years with a mean age of 40.75 . Their age at the time of the first sexual offense ranged from 21-76 with a mean age of 33.24 years. The total number of victims for the adult sub-sample ranged from 1-13.5 with a mean of 1.93 victims. The adult sub-sample was primarily comprised of Caucasian participants (79.8\%) while other racial/ ethnic groups represented were African-American (5.3\%), Asian (1.8\%), Hispanic (1.8\%), Native American (11.4\%), and Other (0.9\%).

These particular sub-samples were chosen because they were evenly divided between intrafamilial (related to the offender) and extrafamilial (not related to or living with the offender) sexual offenders. This distinction is important in regard to this study because the relationship to the victim may influence the modus operandi of the offender, specifically the use of violence to sexually offend. Dividing the samples by intra- and extrafamilial offenders allows equal representation to balance any biases that may exist due to type of relationship to the victim. 
Participants with missing data were excluded from the analyses. Exclusion from the study due to missing data was performed automatically by the data analysis program.

Procedure

Treatment facilities' staff showed potential participants a 10-minute video explaining the study. Participants who identified themselves as wanting to take part in the study listened to a brief presentation by the Principle Investigator, Dr. Keith Kaufman, explaining the purpose of the study. Consent forms were then reviewed, and procedures for completing the questionnaires were described. Following the study description, informed consent forms were signed and collected from each participant. Signed consents remained separate from the questionnaires to maintain confidentiality. Participants were informed that they were not to place their name or any other identifying marks (e.g., numbers) on their questionnaires. Participants were informed that at no time would the consent forms be placed with or matched to the questionnaires.

Data were collected in a group format with approximately 15-25 participants per group. Participants took approximately two hours to complete the study measures. During that time the participants completed the Sexual History Form (SHF), Sexual Fantasy Questionnaire (SFQ), and the Modus Operandi Questionnaire (MOQ). To ensure that the participant's reading skills were adequate, each 
participant completed a brief reading screen (i.e., Wide Range Achievement Test, 1993) with the researcher. Participants whose reading levels were inadequate to complete the questionnaires (less than $6^{\text {th }}$ grade) but who could comprehend the questions were assisted by research staff to complete the questionnaires. Those participants who could not comprehend the questionnaires were excluded from the study. Outpatient participants were compensated $\$ 20$ for their participation.

\section{Measures}

Given the relationship between sexual fantasies (particularly deviant fantasies) and the possible etiology and maintenance of sexual offending, appropriate measurement of sexual fantasies is critical to treatment and preventative practices. This information is important to understand differences between engaging in "normal" (e.g., legal, main stream socially accepted) sexual fantasies and deviant sexual fantasies (e.g., illegal, socially unacceptable). Information gathered using a well-designed fantasy questionnaire may also foster a better understanding of normal sexual fantasies particularly when used with an appropriate community control group.

Sexual Fantasy Questionnaire. The Sexual Fantasy Questionnaire (SFQ; Kaufman, 1993b) consists of 127 self-report items asking participants to rate the frequency with which they experience different types of sexual fantasies. This form is unique in that it collects information regarding deviant as well as normal sexual 
fantasies. This questionnaire also asks for information regarding the frequency of different fantasies. The SFQ consists of eight sub-scales: Traditional/ Romantic (e.g., hugging someone, kissing partner's mouth), Variety of Settings (e.g., having sex in a secluded place, sex in a romantic setting), Variety of Partners (e.g., sex with a stranger, sex with a neighbor), Non-Traditional (e.g., looking at pornographic material, watching others have sex), Mild Coercion (e.g., teasing someone, bribing someone), Aggressive (e.g., hurting partner during sexual activity, sex with children), Global Non-Deviance (e.g., combination of Traditional/Romantic, Variety of Settings, other consensual items), and Global Deviance (e.g., combination of Aggressive and non-consensual items). Each question of the Sexual Fantasy Questionnaire is rated on a 7-point Likert scale from 0 (never in my life) to 6 (two or more times per day).

The SFQ appears to have good validity and reliability. Face validity for the SFQ was demonstrated by such questions as: How often do you fantasize about each of the following - hugging someone, making out, getting married, intercourse in unusual positions, being a virgin, etc.; How often do you have daydreams or fantasies of any kind?; Of all your daydreams or fantasies, how often do they contain sexual thoughts or images? Validity has been established in previously reported studies showing group differences on the form (Daleiden, Kaufman, Hilliker, \& O’Neil, 1998). Preliminary analyses to demonstrate reliability for the Sexual 
Fantasy Questionnaire were conducted on four groups in the Daleiden, Kaufman, Hilliker and O'Neil (1998) study. The four groups for this study were: sexual offenders under 16 years of age, sexual offenders 16-20 years old, non-sexual offending juvenile delinquents, and non-offending college aged males. Alpha reliability coefficients for the Sexual Fantasy Questionnaire were good to excellent for all groups on each of the scales (.79-.98). Reliability coefficient analyses were conducted for the sample for this project to test for internal reliability. Analyses for this particular sample yielded alpha coefficients ranging from .84 to .98 .

Modus Operandi Questionnaire. The Modus Operandi Questionnaire (MOQ; Kaufman, 1994) consists of 365 self-report items asking participants' demographic characteristics, personal abuse history, demographic information regarding children that the offender abused, and ways in which the offender was able to gain access to, compliance with, and the silence of the victim. For MOQ items, participants rated items on a 7-point Likert scale from 0 (never) to 6 (always) to describe the frequency with which they engaged in particular behaviors. This questionnaire was developed with the assistance and input of sexual offenders, victims, and professionals with expertise in the area of sex offender treatment, victim treatment, law enforcement, and sexual abuse prevention. 


\section{Results}

A number of different analytic approaches were used to assess the differences between adult and juvenile sexual offenders. Results will be discussed separately with regard to findings contrasting adults and juveniles as well as to discuss results differentiating between fantasies and the use of violence.

\section{Sexual Fantasies}

A one-way multivariate analysis of variance (MANOVA) was conducted to determine the effect of the two levels of age (juvenile and adult) on the six dependent variables (i.e., the subscales of the SFQ). Due to missing data, 98 juveniles and 97 adults were retained for this analysis. An additional analysis was conducted using mean imputation for those participants missing three or fewer variables resulting in the retention of 108 juveniles and 109 adults. All participants missing four or more variables were excluded from this analysis. Results of this analysis are available upon request; however, overall substantive conclusions did not change. Significant overall differences were found between the two levels of the independent variable on dependent measures, Wilks' $\Lambda=.716, \mathrm{~F}(6,188)=12.44, \mathrm{p}<.001$. The multivariate $\eta^{2}$ based on Wilks' $\Lambda$ was .284 indicating that $28 \%$ of the variance of the dependent variables is associated with the age of the offender. Table 1 contains the means and standard deviations for the dependent variables presented separately for the two levels of age. 
Table 1

Sexual Fantasy Questionnaire Scale Scores (MANOVA)

\begin{tabular}{|c|c|c|c|c|c|}
\hline \multirow[b]{2}{*}{ Fantasy Scale } & \multicolumn{2}{|c|}{ Adult $(\mathrm{N}=97)$} & \multicolumn{2}{|c|}{ Juvenile $(\mathrm{N}=98)$} & \multirow[b]{2}{*}{$\mathrm{p}$} \\
\hline & M & SD & M & $\mathrm{SD}$ & \\
\hline Traditional/ Romantic & 3.26 & 1.39 & 3.15 & 1.55 & .346 \\
\hline Variety of Settings & 1.71 & 1.15 & 2.11 & 1.65 & .000 \\
\hline Variety of Partners & 1.67 & 1.13 & 2.81 & 1.67 & .000 \\
\hline Non-Traditional & 1.86 & 1.15 & 2.29 & 1.72 & .000 \\
\hline Mild Coercion & 0.66 & 0.65 & 1.20 & 1.06 & .000 \\
\hline Aggressive & 0.17 & 0.28 & 0.57 & 0.87 & .000 \\
\hline
\end{tabular}

For each of the four significant Sexual Fantasy scales, the juvenile group exhibited higher mean scores. These results indicate that juvenile sexual offenders report engaging in all types of sexual fantasies, with the exception of Traditional/ Romantic and Variety of Settings, significantly more frequently than adult sexual offenders. Specifically relevant to this project, juvenile sex offenders report experiencing significantly more deviant sexual fantasies than adults. The results of these statistical comparisons are presented in Table 2.

Table 2

Sexual Fantasy Questionnaire Scale (ANOVA)

\begin{tabular}{lcrl}
\hline Fantasy Scale & (Degrees of Freedom) & $\mathrm{F}$ & $\mathrm{p}$ \\
\hline & & & \\
Variety of Settings & $(1,193)$ & 3.84 & .052 \\
Variety of Partners & $(1,193)$ & 30.93 & .000 \\
Nontraditional & $(1,193)$ & 4.04 & .046 \\
Mild Coercion & $(1,193)$ & 18.73 & .000 \\
Aggressive & $(1,193)$ & 18.55 & .000 \\
\hline
\end{tabular}


Violence

A one-way multivariate analysis of variance (MANOVA) was conducted to determine the effect of the two levels of age (juvenile and adult) on the three dependent variables (i.e., physical, threatened, and implied violence). Due to missing data, 108 juveniles and 106 adults were retained for this analysis. Significant overall differences were found between the two levels of the independent variable on each of the three dependent measures, Wilks' $\Lambda=.896, F(3,210)=8.140, p<.001$. The multivariate $\eta^{2}$ based on Wilks' $\Lambda$ was .104 indicating that $10 \%$ of multivariate variance of the dependent variables is associated with the age of the offender. Table 3 contains the means and standard deviations for the dependent variables presented separately for the two levels of age.

Table 3

Violence Scale Scores (MANOVA)

\begin{tabular}{llllll}
\hline & \multicolumn{4}{c}{ Adult $(\mathrm{N}=106)$} & \multicolumn{3}{c}{ Juveniles $(\mathrm{N}=108)$} \\
\cline { 2 - 6 } \multicolumn{1}{c}{ Violence Scale } & $\mathrm{M}$ & $\mathrm{SD}$ & $\mathrm{M}$ & $\mathrm{SD}$ & $\mathrm{p}$ \\
\hline & & & & & \\
Physical Violence & 0.12 & 0.31 & 0.37 & 0.63 & .000 \\
Threatened Violence & 0.03 & 0.14 & 0.21 & 0.47 & .000 \\
Implied Violence & 0.24 & 0.53 & 0.77 & 1.05 & .000 \\
\hline
\end{tabular}

For each of the Violence scales, the juvenile group exhibited higher mean scores. The results indicate that juvenile sex offenders report more use of all three 
types of violence in comparison to the adult sexual offenders. The results of these statistical comparisons are presented in Table 4.

Table 4

Violence Scale (ANOVA)

\begin{tabular}{lccc}
\hline Violence Scale & (Degrees of Freedom) & F & P \\
\hline Physical Violence & & & \\
Threatened Violence & $(3,210)$ & 13.69 & .000 \\
Implied Violence & $(3,210)$ & 14.43 & .000 \\
\hline
\end{tabular}

\section{Discriminant Function}

Juveniles. A discriminant analysis was conducted to determine the extent to which fantasy subscales (i.e., traditional, variety of settings, variety of partners, nontraditional, mild coercion, and aggression) could predict the level of violence (i.e., no violence, implied violence, threatened violence, or physical violence) adopted as part of offending. The tests of equality of group means indicates significant differences in means between four of the predictors: traditional, non-traditional, mild coercion and aggression ( $p$-values range from .00 to .006$)$. Significant differences were not present in the covariance matrices among the four groups ( $p$-value of .07 for the Box's $M$ test). The Wilks' lambda was significant, $\Lambda=.70, \chi^{2}(18, \underline{N}=98)=32.27$, $\mathrm{p}=.02$, indicating that overall the predictors differentiated among the four violence groups. Residual Wilks' lambda were non-significant. Since only the first test was significant, only the first discriminant function was interpreted. 
The within-groups correlations between the predictors and the discriminant functions as well as the standardized weights are presented in Table 5. Based on the coefficients, the mild coercion fantasies demonstrated the strongest relationship with the first discriminant function, while traditional, aggressive and non-traditional fantasies show weaker relationships. On the basis of the results presented in Table 5, the first discriminant function was labeled "Mild Coercion."

Table 5

Standardized Coefficients and Correlations of Predictor Variables With the First Discriminant Functions

\begin{tabular}{lcc}
\hline & $\begin{array}{c}\text { Correlation coefficients with } \\
\text { discriminant functions }\end{array}$ & $\begin{array}{c}\text { Standardized coefficients for } \\
\text { discriminent functions }\end{array}$ \\
& Function 1 & Function 1 \\
\hline Traditional & .69 & .47 \\
Variety of settings & .41 & .78 \\
Variety of partners & .48 & .11 \\
Non-traditional & .70 & .33 \\
Mild coercion & .80 & .58 \\
Aggression & .61 & .41 \\
\hline
\end{tabular}

The means on the discriminant functions are consistent with this interpretation. The offenders who reported the use of implied violence most often (M $=.57)$ had the highest mean scores on the mild coercion fantasies dimension (the first 
discriminant function), while the physical violence group $(\underline{M}=.31)$, the no violence (-.63), and the threatened violence group $(\underline{M}=-.91)$ had lower mean scores.

Figure 4. Juvenile Group Centroids.

\section{Canonical Discriminant Functions}

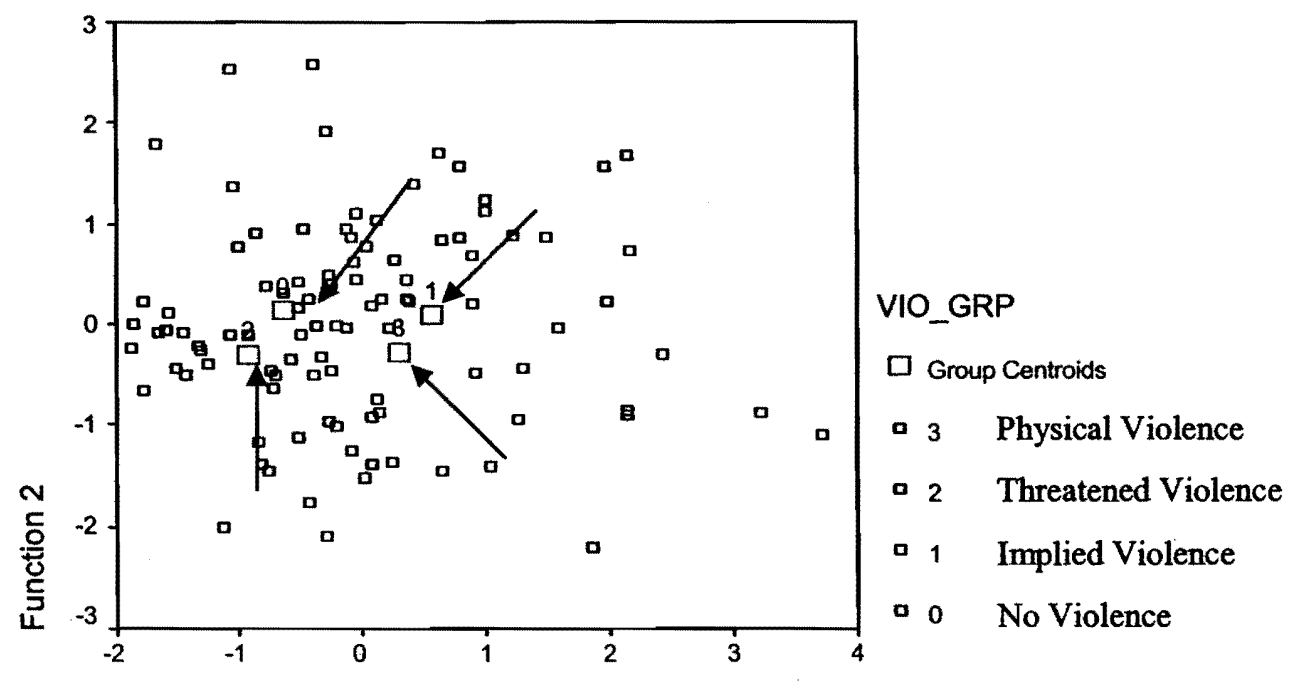

Function 1

In $55 \%$ of the cases, violence group membership was classified correctly.

Classification of cases at chance levels is $32 \%$. Such findings indicate that although there is a relationship between fantasies and behaviors, there are other factors that also influence behavior. To assess how well the classification procedure would predict in a new sample, the estimated percent of sexual offenders classified using the "leave-one-out" technique correctly classified $50 \%$ of cases.

Adults. A discriminant analysis using only the adult data was conducted to determine whether the six predictor variables (fantasy subscales) could predict level 
of violence in sexually offending for this sub-group. The tests of equality of group means indicates significant differences in means between two of the predictors: nontraditional and mild coercion (p-values are .04 and .001 respectively). Tests of equality of group means for the remaining four predictors were non-significant. For the adult data, only three levels of violence domains were evaluated since none of the adult participants endorsed "threatening violence" as their most frequently used form of violence. There were significant differences in the covariance matrices among the three groups (p-value of .00 for the Box's M test). The overall Wilks' lambda was significant $\Lambda=.73, \chi^{2}(12, \underline{\mathrm{N}}=97)=28.63, \underline{\mathrm{p}}=.004$, indicating that the predictors differentiated among the three levels of violence groups. In addition, the residual Wilks' lambda was significant, $\Lambda=.86, \chi^{2}(5, \underline{N}=97)=13.8, \underline{p}=.017$. This test indicated that the predictors differentiated significantly among the three levels of violence groups after partialling out the effects of the first discriminant function. Since these tests were significant, both discriminant functions were interpreted.

The within-groups correlations between the predictors and the discriminant functions as well as the standardized weights are presented in Table 2. Based on these coefficients, the non-traditional fantasies subscale demonstrated the strongest relationship with the first discriminant function, while traditional, variety of settings, mild coercion, and aggression subscales show a weaker relationship and the variety of partner subscale shows a negative relationship. The mild coercion fantasies 
subscale showed the strongest relationship with the second discriminant function, while variety of partners and traditional subscales show a weaker relationship and variety of setting, non-traditional and aggression show negative relationships. On the basis of the results presented in Table 6, the first and second discriminant functions Non-traditional and Coerciveness are respectively labeled for discriminant functions 1 and 2.

Table 6

Standardized Coefficients and Correlations of Predictor Variables with the Two Discriminant Functions

\begin{tabular}{lcccc}
\hline & $\begin{array}{c}\text { Correlation coefficients with } \\
\text { discriminant functions }\end{array}$ & $\begin{array}{c}\text { Standardized coefficients for } \\
\text { discriminant functions }\end{array}$ \\
& Function 1 & Function 2 & Function 1 & Function 2 \\
\hline Traditional & .45 & .25 & .41 & .03 \\
Variety of settings & .17 & .29 & .08 & -.22 \\
Variety of partners & -.14 & .44 & -1.11 & .45 \\
Non-traditional & .59 & .21 & .92 & -.56 \\
Mild coercion & .39 & .90 & .09 & 1.10 \\
Aggressive & .21 & .30 & .30 & -.003 \\
\hline
\end{tabular}

The means for the discriminant functions are consistent with this interpretation. The physical violence group $(\underline{M}=1.35)$ had the highest mean scores on the non-traditional dimension (the first discriminant function), while the implied 
violence group $(\underline{\mathrm{M}}=.02)$ and the no violence group $(\underline{\mathrm{M}}=-.18)$ had lower mean scores. Conversely, the implied violence group $(M=.69)$ had the highest mean scores on the coerciveness dimension, the no violence group $(M=-.22)$ the next highest mean score and the physical violence group $(\mathrm{M}=-.27)$ the lowest mean scores.

Figure 5. Adult Group Centroids.
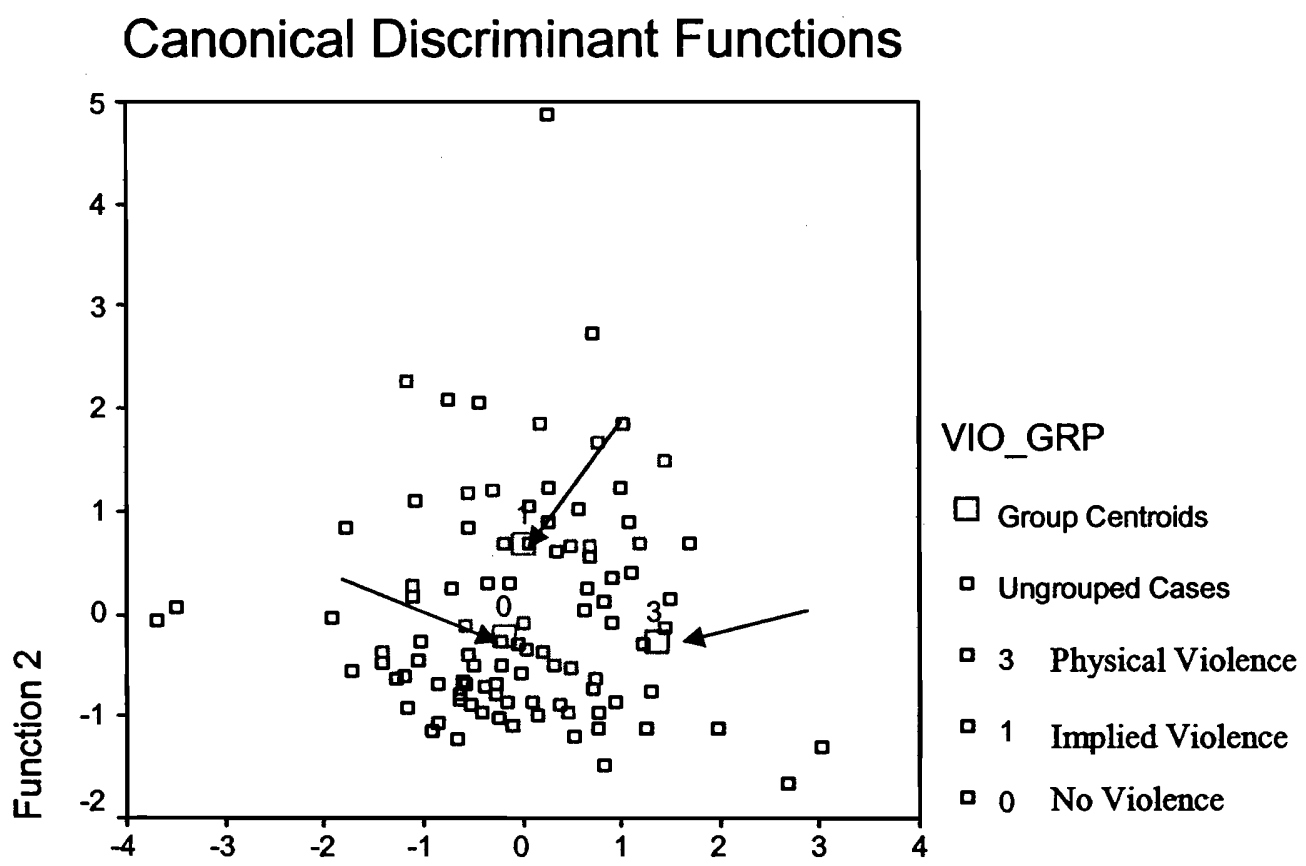

Function 1

Violence group membership was classified correctly in $73 \%$ of the cases. In order to take into account chance agreement, a kappa coefficient was computed and obtained a value of .32, a moderate value. To assess how well the classification procedure 
Adult and Juvenile Sexual Offenders 60

would predict in a new sample, the estimated percent of sexual offenders classified using the leave-one-out technique correctly classified $69 \%$ of cases. 
Adult and Juvenile Sexual Offenders 61

\section{Discussion}

This study examined the difference between adult and juvenile sexual offenders' relationships between their sexual fantasies and their use of violence to sexually offend. Study findings revealed that, on average, juvenile sexual offenders report a greater use of violence and higher frequencies of sexual fantasies than adult sexual offenders. Differences between adult and juvenile sexual offenders are important to explore due to recent studies showing that juveniles may benefit from interventions that are different from the treatment that is provided to adult sexual offenders (Nangle, Hecker, Grover, \& Smith, 2003; Witt, Bosley, \& Hiscox, 2002; Chaffin, Letourneau, \& Silovsky, 2002). Historically, juvenile offenders have been provided assessment and treatment that is based upon methods used with adult sexual offenders. Recent studies suggest that juveniles may respond best to treatment that is directed toward their developmental capabilities (e.g., more fluid sexual arousal and interest patterns resulting in easier modification) rather than approaches developed for adult sexual offenders (Chaffin et al., 2002; Hunter \& Beck, 1994). Developmental Differences

Few studies have been conducted on sexual fantasy. As a result, social and developmental norms for deviant fantasies are relatively unknown. In fact, only one known study has systematically explored the topic of deviant fantasies within a nonoffending population (Leitenberg \& Henning, 1995). In their review, Leitenberg and 
Henning (1995) cite only three studies that have included an examination of the deviant sexual fantasies of non-offenders (Arndt et al, 1985; Grendlinger \& Byrne, 1987; Briere \& Runtz, 1989). Clearly, sexuality in our society has become more acceptable over the past few years and this may have influenced the reporting rates of both deviant and non-deviant sexual fantasies. Juveniles' maturation at a time in our society when more liberal views of sexuality predominate (Singer \& Singer, 2001) may have fostered adolescent participants' greater comfort in reporting their deviant as well as non-deviant sexual fantasies. Adults who grew up with more sexually conservative media and culture may not be as desensitized to sexual topics as juveniles of the MTV generation (Singer \& Singer, 2001).

Developmental and cultural norms may account for some of the differences found in this study. The analysis exploring differences between adults and juveniles and their frequency of sexual fantasies revealed that juveniles engage in more sexual fantasies than adults. Most relevant to this study, juvenile sexual offenders were found to engage in more deviant fantasies than their adult counterparts. The only fantasy scale for which the adults endorsed higher mean frequencies was the "Traditional/ Romantic" scale; however, the difference did not reach significance. Differences between adults' and juveniles' sexual fantasies may indicate developmental differences in sexual exposure, experiences and expectations. Such 
differences may also support the recent findings indicating a need for specialized treatment based upon the age of the offender.

One theory to explain juveniles' greater number of deviant fantasies would suggest that they are more involved in exploring their sexuality at this time in their lives. In general, juveniles have been found to engage in a greater variety of sexual activities than adults (Daleiden et al., 1998). An alternative exploration may be related to the greater societal tolerance for sexual exploration in recent years. Evidence suggests that in Western society, sexual experimentation is tolerated to a greater extent in juveniles than in adults (Gil \& Johnson, 1993). By middle adulthood, members of our society are expected to conform to "traditional" societal norms (e.g., involvement in a committed relationship). However, in adolescents and young adults, tolerance is typically higher for sexual exploration including what might otherwise be considered "promiscuity" as well as involvement in other less socially desirable sexual activities (Gil \& Johnson, 1993). Adults may respond to particular behaviors with such comments as "boys will be boys" or "that's just kid's play." While a paucity of research is available regarding juveniles' sexual fantasies, it may be assumed that juveniles' greater sexual exploration may be related to more varied and frequent sexual fantasies, as was demonstrated in this study. Due to the lack of literature describing non-offending population's sexual fantasies, it is impossible to draw conclusions about juvenile offenders' fantasies in relation to 
community controls. Further, it is not known if the differences between adult and juvenile offending populations identified in this study may be present in community samples of adults and juveniles.

In addition to variations in fantasy patterns, differences were also found between adults' and juveniles' offense related use of violence. Developmental differences may also account for these findings. Juveniles were found to have used or threatened violence as part of their sexual offenses more frequently than adult sexual offenders. This may have been related to their level of social skills development. Over time adults may develop a greater ability to coerce and manipulate children into engaging in sexual activities. This may be as a result of their superior communication skills or their status as authority figures. Adult sexual offenders may also be more patient and methodical in the time they are willing to take in convincing a child to participate in sexually abusive activities (Kaufman et al., 1998). In contrast, juvenile offenders have been found to be more impulsive and resort to physical force or threats of force to coerce child participation (Kaufman, et al., 1998). Adult offenders may see physical force as an approach of last resort. They may be more aware that force, while highly likely to result in compliance, may increase the risk of disclosure. On the other hand, the impulsivity typically seen in adolescents may inhibit their consideration of consequences physically violent approaches may engender. Findings in the literature (e.g., Kaufman et al., 1998) 
support the fact that juveniles tend to use a greater number of modus operandi strategies (i.e., threats, physical force) than adults. Adults may have the foresight to understand that patience and less intrusive strategies may lead to compliance and reduce potential for disclosure, while juveniles resort to whatever means necessary at the time to accomplish their goal. Adults also have more power and authority due to their age and physical size further increasing their ability to sexually offend without the use of more violent modus operandi.

\section{Social Desirability}

It is feasible that study findings may, in large part, reflect adults' greater concern with how they may be perceived if they report a high frequency of deviant sexual fantasies. Adults' higher level of acculturation as well as social learning may increase the impact of social pressures and understanding of socially desirable behaviors. Social desirability has been found to influence individuals' responses regarding sexual and risky behaviors even on anonymous questionnaires (Fick, 2001; Meston, Heiman, Trapnell, \& Paulhus, 1998). Fink (2001) found that participants with an increased sense of social desirability reported lower rates of risk behaviors. Highlighted in this study was the need for researchers studying sexual behaviors to account for social desirability. Those participants who are more concerned with how they will be perceived reported fewer sexual and risky behaviors. Because sexual offending behavior is both sexual and risky, consideration must be given to self- 
report measures regarding such behaviors. Meston and colleagues (1998) also found social desirability biases in anonymous questionnaires regarding sexual behavior, attitudes and fantasies. They investigated the impact of two forms of social desirability (self-deceptive enhancement and impression management) on sexuality self-reports. These included reports regarding sexual behaviors as well as fantasies. Findings reveal that while self-deceptive enhancement may have been controlled, in the results impression management remained significant. The researchers conclude that even with anonymous questionnaires, social desirability may have an influence in reports of sexual behavior. Implications from such studies suggest there may be underreporting in research examining the behaviors and fantasies of sexual offenders due to social desirability.

In some instances, social desirability seems to exert greater influence as individuals age and become more involved in society (Ray \& Lovejoy, 2003). As people become more experienced and have greater exposure to societal expectations, they begin to solidify their identity and how they would like others to see them. Less socially acceptable behaviors are minimized or denied to preserve a more socially positive image. Zolondek, Abel, Northey, and Jordan (2001) found that adolescent sex offenders with low social desirability scores reported more sexual offenses than did offenders with higher scores of social desirability. Thus, it is possible that adults may have minimized the frequency of their deviant sexual fantasies. At the same 
time, juveniles may be less influenced by societal pressures to minimize less desirable behaviors and may have accurately reported more frequent sexual fantasies in general as well as more deviant sexual fantasies.

While bias due to social desirability is possible, consideration must be given to the fact that questionnaires were completed in an anonymous fashion. This may have minimized the impact of social desirability. In addition, research for this study was collected only from offenders who had been involved in treatment. Such offenders would have been well practiced at disclosing information regarding sexual behaviors and fantasies, thus increasing the likelihood of accurate disclosure. As Leitenberg and Henning (1995) found, even small populations of people who are not known to have sexually offended admitted to engaging in sexually deviant fantasies. However, at present it is still unknown if those small numbers truly represent the population of individuals who engage in such deviant fantasies or if there are more people who do not report such fantasies due to social desirability even with anonymous questionnaires. When a questionnaire is administered anonymously it is still possible that a proportion of participants may be uncomfortable admitting to such deviant fantasies due to the associated social stigma.

\section{Fantasies and Violence}

Although the subject of sexual offenders' sexual fantasies have just begun to be studied empirically, the majority of offender treatment programs incorporate some 
component of fantasy exploration/modification (Dandescu \& Wolfe, 2003). This emphasis is interesting given the paucity of literature exploring, let alone demonstrating, an empirical relationship between fantasy and behavior. Studies have shown that deviant sexual fantasy is not unheard of in non-offending populations (Leitenberg \& Henning, 1995). However, it is assumed that sexually deviant fantasies play a potentiating role in offender' perpetration (Laws \& Marshall, 1990; Pithers, 1990). Numerous studies have attempted to explore deviant fantasies of offenders but no study is available to empirically demonstrate a relationship between deviant fantasy and deviant behavior. Moreover, studies comparing identical data between adult and juvenile sex offenders is very rare. It was this fact that led to the current investigation. The current data allows for not only an investigation of the relationship between fantasy and behavior but also a comparison between adult and juvenile sexual offenders. Given the clinical implications of such findings, it is important to examine the differences between adults and juveniles especially in light of research suggesting significant clinical differences between the two populations (Nangle, et al., 2003; Witt, et al., 2002; Chaffin, et al., 2002).

Discriminant function analyses yielded interesting information for both adult and juvenile participants. Significant differences were found for juvenile offenders on sexual fantasy subscales related to traditional, mild coercion, and aggressive fantasies. Juvenile participants' fantasies were found to differentiate between the 
four levels of violence (no violence, implied, threatened, and physical violence) included in this study. Overall, the strongest relationship found for offenders was between their fantasies of mild coercion and their use of implied violence. Findings of this nature would be expected. The use of tactics such as talking someone into doing something they do not really want to do is similar to the items endorsed for implied violence. This category of violence includes the use of such things as placing a weapon where the victim can see it or hoping the victim would think the offender would hurt them even if the offender did not say they would do so. Those who fantasized most often about coercing a victim into complying were also most likely to imply to the victim that something would happen to them if they did not cooperate with the sexually abusive acts. In both the coercive fantasies and the implied violence categories, the victim was not physically harmed or overtly threatened with harm. Implying violence involves more subtle forms of manipulation. These findings are consistent with results obtained by Hunter, Hazelwood, Slesinger, and David (2000). Hunter and his colleagues found that juveniles who sexually offended against children were most likely to use intimidation rather than physical force. The next strongest relationship for those in the current study who reported fantasies of mild coercion were the juveniles who reported using physical violence to offend. Perhaps those juveniles who use physical force engage in coercive fantasies in an attempt to modify offending behaviors to decrease the potential of their discovery. As Laws and 
Marshall (1990) have suggested, juveniles who engage in coercive fantasies may be planning their strategies for future offenses. Since juveniles tend to have less impulse control than adults, these juveniles may not have the experience necessary to predict consequences for using physical force. Through coercive fantasy rehearsals, juvenile offenders may be attempting to modify the offense to be less physically harmful. Although juveniles may not be able to predict being caught by using physically harmful offending tactics, offenders may experience negative consequences directly from the child (e.g., crying, physically resisting). These negative consequences may be aversive to the offender. Thus by reducing the negative consequences from the victim the offender also reduces the chance of being caught. Such changes in offending may take place through a series of fantasy modification and offending behavior over time (Marshall, 1990).

Juveniles were correctly classified based on their fantasies as to the degree of violence used $55 \%$ of the time. This indicates that although fantasies and behaviors (i.e., the use of violence) in offending are related, fantasies are not the only component contributing to the way in which a person offends. However, considering that $32 \%$ of the juveniles would be classified correctly at chance levels, there appears to be a fairly strong relationship between their fantasies and behaviors. These findings suggest that there is an empirical relationship between the fantasies a juvenile offender engages in and the offending behaviors that they actually commit. 
Specifically, juveniles who engage in fantasies involving mild coercion are likely to use implied violence to commit a sexual offense. Although there are many factors that influence a juvenile's decision to sexually offend, being able to classify juveniles at levels greater than chance leads to a strong argument for certain therapeutic practices. Juveniles who have used particular modus operandi strategies to offend may be engaging in particular types of sexually deviant fantasy on a regular basis. As this study and others (e.g., Daleiden, et al., 1998) have demonstrated, juveniles engage in a broad array of sexual fantasies. This fantasy exploration may, in fact, be related to particular offending behaviors. Empirical support for this relationship between fantasy and behavior is consistent with therapeutic practices related to the monitoring and modification of fantasy content. The current practices of incorporating fantasy modification in sex offender treatment with juveniles may be an important factor in decreasing recidivism. If deviant fantasies can be detected and modified there may be a decrease in associated deviant behavior. Certainly this topic should be further investigated. Although this study focused exclusively on behaviors involving violence in sexual offending, future replications should include other types of behaviors (e.g., bribery, relationships to the victim or the victim's caregiver, etc.) as well. Perhaps sexual fantasies will be found to have a stronger role in non-violent behaviors related to sexual offending as well. 
A similar relationship was uncovered between fantasies and offending in adult sexual offenders. A significant difference was found between adult offenders' use of non-traditional fantasies and fantasies involving mild coercion. Overall, significant differences for adult offenders were evident on the use of the three types of violence (i.e., physical force, implied violence, and no violence). None of the adult sexual offenders reported having used threats of violence as the most common form of violence. The adults who reported using non-traditional fantasies (e.g., watching others have sex), however, were more likely to use physical force to sexually offend. Interestingly, those who used physical force to offend were more likely to engage in non-traditional fantasies rather than aggressive fantasies. This may, however, reflect the types of physical force utilized. The data analysis did not examine the degree of physical force used by offenders (e.g., pulled by the arm, tied the victim up, etc.). It is possible that the relationship found between physical force and non-traditional fantasies may be better understood if the exact nature of the physical force was provided. For instance, in this study physical force may have been any behavior along a continuum from taking the child by the hand to bring them along to tying up the child. The specific type of physical force used along this continuum may help explain the relationship of physical force to non-traditional fantasies, particularly if the force was on the less coercive end of the range. These findings would be considered surprising given literature indicating that juveniles are 
more likely to use physical force to offend (Fehrenbach et al., 1986; Kaufman et al., 1998). It would be expected that non-traditional fantasies (e.g., masturbating your partner, watching others have sex, etc.) would more likely be related to coercive type behaviors such as implied violence. Implied violence was, in fact, the next most common form of violence used by those who reported engaging in non-traditional fantasies. Again, it is interesting that the strongest relationship between fantasy and behavior does not reflect fantasies that are of the same content as the behaviors endorsed. Pithers' (1990) as well as Laws and Marshall's (1990) have posited that offending behaviors are scripted in fantasies. If this were true, one would expect aggressive fantasies to be more directly related to physical force.

Findings also revealed that adult offenders who used mild coercion fantasies were most likely to engage in implied violence when they offended. Similar to juvenile offenders, this type of violence-fantasy relationship would be expected if only fantasies and behaviors were related. For example, it has been suggested that an offender attempting to manipulate a victim into compliance, may have visualized such tactics in their pre-offense fantasies (Laws \& Marshall, 1990). They may try to cajole a victim into cooperation and may place a threatening item where the victim can see it. Neither of these tactics are directly threatening to the victim but they may convey the offender's intentions to harm the victim should they not comply. 
With $73 \%$ of the adult offenders being classified correctly, findings appear to be similar for adults and juveniles. Chance level of classification for adults is $50 \%$. From these findings it appears that the type of fantasy an adult offender engages in predicts at similar levels for the type of violence that they will use in their sexual offense when compared to juvenile offenders. Correct classification rates for violence-based types of fantasy were similar for adults and juveniles. However, juveniles seem to have a more intuitive pattern of the relationships between fantasy and behavior. For example, it would be expected that mild coercive fantasies and implied violence would be related; however, adult data revealed the strongest relationship between non-traditional fantasies and physical force. Perhaps these findings reflect the development of a conditioned relationship between particular fantasies and behaviors that adults have developed over time. These age-based differences may indicate the need for tailored types of intervention. Continued research into the differences between adult and juvenile offenders would also be beneficial given the recent studies showing that there are indeed distinct differences in offending patterns and potentially in offending etiology of adults and juveniles (Chaffin et al., 2002; Kaufman et al., 1998). Study findings suggest both a more direct relationship between fantasy and behavior for adult offenders as well as the need for greater treatment intensity. 
Although this study found a relationship between fantasies and behaviors for both adults and juveniles, there were distinct differences in those relationships. While juveniles had an intuitive pattern of relationships (e.g., mildly coercive fantasies predicted implied violence), adults did not (e.g., non-traditional fantasies predicted physical violence). Such differences should be considered when designing treatment approaches for these two distinct populations. Juveniles' more intuitive patterns of relationships between fantasy and behavior may lend more support to direct intervention with fantasy modification procedures. This may include fantasy logs for monitoring and fantasy modification techniques (e.g., thought stopping, covert desensitization). However, the unexpected pattern of relationship between non-traditional fantasies and physical force found in the adult population appears to be more complicated. Non-traditional fantasies (e.g., masturbating your partner, watching others have sex, giving oral sex) while not romanticized in the media, are often portrayed as highly sexually stimulating. Perhaps adults who are fantasizing about these behaviors and engaging children in sexually abusive activity may not plan to use physical force, but may resort to it when things do not go as planned. For instance, an adult may have read about or seen these behaviors in videos with adults. They may even have fantasized about them. However, when they tried to engage the child in behaviors of this nature, the child was not cooperative. As a result the offender may resort to force. However, the pairing of the fantasy and the behavior 
over time may reinforce the relationship and increase sexual arousal. Offending behaviors developed in such a fashion may require different types of intervention than simply thought stopping or cognitive restructuring. Disrupting fantasy-behavior relationships of this nature may require stronger interventions (e.g., aversive conditioning) that addresses underlying mechanisms.

\section{Study limitations}

Although this study yielded interesting findings, several limitations must be considered. First, a caution regarding the study sample should be noted. Offenders who participated have been discovered and convicted of sexual offenses. As such they may be different from offenders who have not yet been caught. Offenders who have been identified may engage in different repertoire of offense related behaviors that may increase their chances of detection. There may also be differences in both the kinds of offenses they committed and the types or frequencies of fantasies in which they engage. Moreover, findings of this study may reflect common developmental differences between adults and juveniles and may not be unique to sexual offenders. Future comparisons between sexually offending populations of adults and juveniles as well as non-offending controls may assist in understanding the role of developmental differences in the relationship between fantasy and behavior. 
A second study limitation may involve the potential for inaccurate selfreporting of information. Some studies have shown that even non-convicted populations (e.g., controls) have reported engaging in deviant fantasies at significant rates (Briere \& Runtz, 1989). The possibility that research participants were exaggerating or minimizing their responses must be considered. However, unlike behaviors such as drug use, which may be much more common in certain populations (e.g., college students), child sexual abuse is much more socially unacceptable and therefore, less desirable. For example, a college student may brag about or at least discuss their illegal drug use with friends, but very few child molesters would discuss their behaviors with their non-offending friends or family. The social ramifications for disclosing sexual offending behavior is often much more severe than for other criminal acts. For instance, convictions for drug use may include incarceration and supervision (e.g., parole or probation). However, at the end of these sanctions the offender may return to a relatively normal social life. Convicted sex offenders, however, may experience ongoing social consequences with the addition of lifetime sex offender registration, restrictions on types of employment, community notification, and significant social stigma. Such social stigma may have limited the disclosure of sexually deviant thoughts or behaviors. It should be noted, however, that the anonymous nature of this research may increase the likelihood of honest responses even given these issues. Future studies may 
consider the inclusion of a social desirability measure as a way of detecting socially desirable responding.

Future studies should also examine the relationships between fantasies and other problematic behaviors (e.g., robbery, drug use, assaultive behavior) in community controls. Establishing a relationship between fantasies and problem behaviors in non-sexual offending community samples may speak to the role of offense planning in fantasy and its relationship to the topography of offending.

Finally, future research should investigate other behaviors in offending (e.g., bribery, pseudo friendships with the victim, use of authority) and their relationship to the types and frequencies of fantasies. Additional research may uncover distinct patterns of both offending and fantasies that may have implications for the development of new approaches to the treatment of sexual perpetrators. Additional research should also seek to develop normative information regarding fantasy patterns in the general population as well as in other forensic populations. Differences in fantasies may assist in the identification of cognitive distortions and the potential for deviant behavior. Given that this study found a relationship between fantasy and violence, broadening our knowledge in this area is likely to foster the development of new assessment and treatment approaches. 


\section{References}

Abel, G.G., Becker, J.V., Mittelman, M., Cunningham-Rathner, J. Rouleau, J. \& Murphy, W. (1987). Self-reported sex crimes of nonincarcerated paraphiliacs. Journal of Interpersonal Violence, 2, 3-25.

Abel, G.G., Mittleman, M, \& Becker, J.V. (1985). Sexual offenders: Results of assessment and recommendations for treatment. In M. Ben-Aron, S. Hucker, and C. Webster (Eds.), Clinical Criminology: The Assessment and Treatment of Criminal Behavior (pp. 191-205). Toronto: Clarke Institute of Psychiatry, University of Toronto.

Abel, G.G, Osborn, C.A, \& Twigg, D.A. (1993). Sexual assault through the life span: Adult offenders with juvenile histories. In H.E. Barbaree, W.L. Marshall (Eds); et al. The juvenile sex offender (pp. 104-117).

American Psychiatric Association. (2000). Diagnostic and statistical manual of mental disorders (Fourth Edition, Text Revised). Washington, DC: Author.

Ames. L.B. (1966). Children's stories. Genetic Psychology Monographs, 73, 337396.

Araji, S.K. (1997). Sexually aggressive children: Coming to understand them. Thousand Oaks, CA: SAGE Publications. 
Arndt, W.B., Foehl, J.C., \& Good, F.E. (1985). Specific sexual fantasy themes: A multidimensional study. Journal of Personality and Social Psychology, 48, $472-480$.

Bandura, A. (1973). Aggression: A social learning analysis. Englewood Cliffs, NJ: Prentice-Hall.

Barbaree, H.E., Hudson, S.M., \& Seto, M.C. (1993). Sexual assault in society: The role of the juvenile offender. In H.E. Barbaree, W.L. Marshall, \& S.T. Hudson (Eds.), The juvenile sex offender (pp. 1-24). New York: The Guilford Press.

Barbaree, H.E., Marshall, W.L., \& Hudson, S.M. (Eds.). (1993). The juvenile sex offender. New York: The Guilford Press.

Becker, J.V. (1988). Adolescent sex offenders. The Behavior Therapist, 11, 185-187.

Becker, J.V. \& Stein, R.M. (1991). Is sexual erotica associated with sexual deviance in adolescent males? International Journal of Law \& Psychiatry, 14(1-2), 85 95

Bower, G.H., Bootzin, R.R., \& Zajonc, R.B. (1987). Principles of psychology today. NY: Random House, Inc.

Briere, J. \& Conte, J.R. (1993). Self-reported amnesia for abuse in adults molested as children. Journal of Traumatic Stress, 6, 21-31. 
Briere, J., \& Elliott, D.M. (1994). Immediate and long-term impacts of child sexual abuse. Future of Children, 4, 54-69.

Briere, J. \& Runtz, M. (1989). University males' sexual interest in children: Predicting potential indices of "pedophilia" in a nonforensic sample. Child Abuse \& Neglect, 13, 65-75.

Burton, D.L. \& Smith-Darden, J. (2000). 2000 Nationwide survey of sexual buser treatment and models summary data. The Safer Society Foundation, Inc.

Bushman, B.J. \& Huesmann, L.R. (2001). Effects of television violence on aggression. In D.G. Singer \& J.L. Singer (Eds.), Handbook of children and the media (pp. 223-254). Thousand Oaks, CA: Sage Publications, Inc.

Butz, C. \& Spaccarelli, S. (1999). Use of physical force as an offense characteristic in subtyping juvenile sexual offenders. Sexual Abuse: A Journal of Research and Treatment, 11, 217-232.

Chaffin, M., Letourneau, E., \& Silovsky, J.F. (2002). Adults, adolescents, and children who sexually abuse children: A developmental approach. In J.E.B. Myers, L. Berliner (Eds); et al. The APSAC handbook on child maltreatment (2nd ed.). (pp. 205-232). Thousand Oaks, CA, US: Sage Publications, Inc.

Cohen, M.L., Garofalo, R., Boucher, R., \& Seghorn, T. (1971). The psychology of rapists. Seminars in Psychiatry, 3(3), 307-327. 
Cook, R.F., Fosen, R.H., \& Pacht, A. (1971). Pornography and the sex offender: Patterns of previous exposure and arousal effects of pornographic stimuli. Journal of Applied Psychology, 5, 503-511.

Cooper, Arnold M. (1986). What men fear: The facade of castration anxiety. In G.I. Fogel, F.M. Lane (Eds), et al. The psychology of men: Psychoanalytic perspectives. (pp. 113-130).

Daleiden, E.L., Kaufman, K.L., Hilliker, D.R., \& O’Neil, J.N. (1998). The sexual histories and fantasies of youthful males: A comparison of sexual offending, nonsexual offending, and nonoffending groups. Sexual Abuse: A Journal of Research and Treatment, 10, 195-209.

Dandescu, A. \& Wolfe, R. (2003). Considerations on fantasy use by child molesters and exhibitionists. Sexual Abuse: A Journal of Research and Treatment, 15(4), 297-305.

Dhawan, S. \& Marshall, W.L. (1996). Sexual abuse histories of sexual offenders. Sexual Abuse: Journal of Research \& Treatment, 8, 7-15.

English, D.J. \& Ray, J.A. (1991). Children with sexual behavior problems: A behavioral comparison. Olympia, WA: Department of Social and Health Services. 
Fehrenbach, P.A., Smith, W., Monastersky, C. \& Deisher, R.W. (1986). Adolescent sexual offenders: Offender and offense characteristics. American Journal of Orthopsychiatry, 56, 225-233.

Fick, J.E. (2001). The validity of self-reported sexual behaviors: Engineering reactivity with a bogus pipeline. Dissertation Abstracts International: Section B: the Sciences \& Engineering, 62(1-B),599.

Finkelhor, D. (1980). Risk factors in the sexual victimization of children. Child Abuse and Neglect, 4, 265-273.

Finkelhor, D., Araji, S.K., Baron, L., Browne, A., Peters, S.D., \& Wyatt, G.E. (1986). A sourcebook on child sexual abuse. Beverly Hills, CA; SAGE Publications.

Finkelhor, D. \& Hotaling, G.T. (1984). Sexual abuse in the National Incidence Study of Child Abuse and Neglect: An appraisal. Child Abuse \& Neglect,8, 23-32.

Freud, S. (1962). Creative writers and daydreaming. In J. Strachy (Ed.), The standard edition of the complete psychological works of Sigmund Freud (Vol. 9, pp. 142-152). London.

Geen, R. \& O'Neal, E. (1969). Activation of cue-elicited aggression by general arousal. Journal of Personality and Social Psychology, 11, 289-292.

Gil, E. \& Johnson, T.C. (1993). Sexualized children: Assessment and treatment of sexualized children and children who molest. Launch Press. 
Gold, S.R. \& Gold, R.G. (1991). Gender differences in first sexual fantasies. Journal of Sex Education and Therapy, 17, 207-216.

Goldstein, M.J \& Kant, H.S. (1973). Pornography and sexual deviance: A report of the Legal and Behavioral Institute. Beverly Hills, California.

Grendlinger, V. \& Byrne, D. (1987). Coercive sexual fantasies of college men as predictors of self-reported likelihood to rape and overt sexual aggression. Journal of sex research, 23, 1-11.

Groth, A.N. \& Birnbaum, H.J. (1978). Adult sexual orientation and attraction to underage persons. Archives of Sexual Behavior, 7, 175-181.

Gruber, K.J., \& Jones, R.J. (1983). Identifying determinants of risk of sexual victimization of youth. Child Abuse and Neglect, 7, 17-24.

Halliday, L. (1985). Sexual abuse: Counseling issues and concerns. Campbell River, BC: Ptarmigan Press.

Herman, J.L. (1990). Sex offenders: A feminist perspective. In W.L. Marshall, D.R. Laws, \& H.E. Barbaree (Eds.), Handbook of sexual assault: Issues, theories, and treatment of the offender (pp. 177-193). New York, NY: Plenum Press.

Herman, J.L., \& Hirschman, L. (1981). Families at risk for father-daughter incest. American Journal of Psychiatry, 138, 967-970.

Hindman, J.L. \& Peters, J.M. (2001). Polygraph testing leads to better understanding adult and juvenile sex offenders. Federal Probation, 65, 8-15. 
Adult and Juvenile Sexual Offenders 85

Herman, J.L., \& Schatzow, E. (1987). Recovery and verification of memories of childhood sexual trauma. Psychoanalytic Psychology, 4, 1-14.

Hunt, M. (1974). Sexual behavior in the 70's. Chicago: Playboy Press.

Hunter, J.A. \& Becker, J.V. (1994). The role of deviant sexual arousal in juvenile sexual offending: Etiology, evaluation, and treatment. Criminal Justice \& Behavior, 21, 132-149.

Hunter, J.A., Childers, S.E., Gerald, R., \& Esmaili, H. (1990). An examination of variables differentiating clinical subtypes of incestuous child molesters. International Journal of Offender Therapy \& Comparative Criminology, 34, 95-104.

Hunter, J.A., Goodwin, D.W., \& Becker, J.V. (1994). The relationship between phallometrically measured deviant sexual arousal and clinical characteristics in juvenile sexual offenders. Behaviour Research \& Therapy, 32, 533-538.

Jaffe, P.G., Sudermann, M., \& Reitzel, D. (1992). Working with children and adolescents to end the cycle of violence: A social learning approach to intervention and prevention programs. In R. Peters, R. McMahon, \& V. Quinsey (Eds.), Aggression and violence throughout the life span (pp.83-99). Newbury Park, CA: SAGE Publications, Inc.

Kaufman, K.L. (1993a). Sexual history form. Available from author, Portland, OR: Portland State University. 
Adult and Juvenile Sexual Offenders 86

Kaufman, K.L. (1993b). Sexual fantasy questionnaire. Available from author, Portland, OR: Portland State University.

Kaufman, K.L. (1994). Modus Operandi Questionnaire. Available from author, Portland, OR: Portland State University.

Kaufman, K.L., Holmberg, J.K., Orts, K.A., McCrady, F.E., Rotzien, A.L., Daleiden, E.L., \& Hilliker, D.R. (1998). Factors influencing sexual offenders' modus operandi: An examination of victim-offender relatedness and age. Child Maltreatment, 3, 349-361.

Kozol, H.L. (1971). Myths about the sex offender. Medical Aspects of Human Sexuality, 5, 50-62.

Landis, J.T. (1956). Experiences of 500 children with adult sexual deviants. Psychiatric Quarterly Supplement, 30, 91-109.

Laws, D.R. \& Marshall, W.L. (1990). A conditioning theory of the etiology and maintenance of deviant sexual preference and behavior. In W.L. Marshall, D.R. Laws, \& H.E. Barbaree (Eds.), Handbook of sexual assault: Issues, theories, and treatment of the offender. NY, NY: Plenum Press.

Laws, D. R., \& O'Donohue, W. T. (Eds). (1997) Sexual deviance: Theory, assessment, and treatment. New York: The Guilford Press.

Leitenberg, H. \& Henning, K. (1995). Sexual fantasy. Psychological Bulletin, 117, 469-496. 
Levin, S.M. \& Stava, L.J. (1987). Personality characteristics of sex offenders: A review. Archives of Sexual Behavior, 16, 57-79.

Loftus, E.F., Polonsky, S., \& Fullilove, M.T. (1994). Memories of childhood sexual abuse: Remembering and repressing. Psychology of Women Quarterly, 18, $67-84$

Longo, R.E. \& Groth, A.N. (1983). Juvenile sexual offenses in the histories of adult rapists and child molesters. International journal of offender therapy and comparative criminology, 27, 150-155.

Looman, J. (1995). Sexual fantasies of child molesters. Canadian Journal of Behavioural Science, 27, 321-332.

Malmquist, C.P. (1972). Juvenile sex offenders. In H.L. Resnik \& M.E. Wolfgang (Eds.), Sexual behaviors: Social, clinical and legal aspects (pp. 76-77). Boston: Little, Brown.

Marshall, W.L. (1992). CSRF distinguished lecture--The social value of treatment for sexual offenders. The Canadian Journal of Human Sexuality. 1, 109-114.

Marshall, W.L., Barbaree, H.E., \& Eccles, A. (1991). Early onset and deviant sexuality in child molester. Journal of Interpersonal Violence, 6, 323-335.

Marshall, W.L. \& Marshall, L.E. (2000). The origins of sexual offending. Trauma, Violence, \& Abuse, 1, 250-263. 
Matthews, R., Hunter, J.A., \& Vuz, J. (1997). Juvenile female sexual offenders: Clinical characteristics and treatment issues. Sexual Abuse: Journal of Research \& Treatment,9, 187-199.

McCloskey, L.A. \& Bailey, J.A. (2000). The intergenerational transmission of risk for child sexual abuse. Journal of Interpersonal Violence, 15(10), 1019-1035.

McGrath, R.J, Cumming, G., Livingston, J.A, \& Hoke, S.E. (2003). Outcome of a treatment program for adult sex offenders: From prison to community. Journal of Interpersonal Violence, 18(1), 3-17.

McKibben, A., Proulx, J., \& Lusignan, R. (1994). Relationships between conflict, affect and deviant sexual behaviors in rapists and pedophiles. Behaviour Research \& Therapy, 32, 571-575.

Meston, C.M., Heiman, J.R., Trapnell, P.D., \& Paulhus, D.L. (1998). Socially desirable responding and sexuality self-reports. Journal of Sex Research, $35(2), 148-157$.

Nangle, D.W., Hecker, J.E., Grover, R.L., \& Smith, M.G. (2003). Perspective taking and adolescent sex offenders: From developmental theory to clinical practice. Cognitive \& Behavioral Practice, 10, 73-84.

Neufeldt, V. \& Sparks, A.N. (Eds.). (1995). Webster's new world compact school and office dictionary. NY, NY: Simon \& Schuster Macmillan Company. 
Newmann, J.P., Greenley, D., Sweeney, J.K., \& Van Dien, G. (1998). Abuse histories, severe mental illness, and the cost of care. In B. Lubotsky Levin and A. Blanch (Eds.), Women's mental health services: A public health perspective. (pp. 279-308). Tampa, FL: University of South Florida. Oliver, M.B. (1994). Portrayals of crime, race, and aggression in "reality-based" police shows: A content analysis. Journal of Broadcasting and Electronic media, 38, 179-192.

Paik, H., \& Comstock, G. (1994). The effects of television violence on antisocial behavior: A meta-analysis. Communication Research, 21, 516-546.

Pfiffner, L.J, \& O'Leary, S.G. (1987). The efficacy of all-positive management as a function of the prior use of negative consequences. Journal of Applied Behavior Analysis, 20(3), 265-271.

Pithers, W.D. (1990). Relapse prevention with sexual aggressors: A method for maintaining therapeutic gain and enhancing external supervision. In W.L. Marshall, D.R. Laws,(Ed), et al. Handbook of sexual assault: Issues, theories, and treatment of the offender. Applied clinical psychology. (pp. 343-361).

Pithers, W.D., Beal, L.S., Armstrong, J., \& Petty, J. (1989). Identification of risk factors through clinical interviews and analysis of records. In D.R. Laws (Ed). Relapse prevention with sex offenders. (pp. 77-87). 
Adult and Juvenile Sexual Offenders 90

Plaud, J.J. \& Bigwood, S.J. (1997). The relationship of male self-report of rape supportive attitudes, sexual fantasy, social desirability and physiological arousal to sexually coercive stimuli. Journal of Clinical Psychology, 53, 935942.

Prentky, R.A. \& Burgess, A.W. (1990). Rehabilitation of child molesters: A costbenefit analysis. American Journal of Orthopsychiatry, 60, 108-117.

Proulx, J., McKibben, A., \& Lusignan, R. (1996). Relationships between affective components and sexual behaviors in sexual aggressors. Sexual Abuse: Journal of Research \& Treatment, 8, 279-289.

Ray, J.J. \& Lovejoy, F.H. (2003). Age-related social desirability responding among Australian women. Journal of Social Psychology, 143, 669-671.

Remer, R. \& Elliott, J.E. (1988). Management of secondary victims of sexual assault. International Journal of Family Psychiatry, 9(4), 389-401.

Remer, R. \& Ferguson, R.A. (1998). Treating traumatized partners: Producing secondary survivors of PTSD. In C. Figley (Ed.), Burnout in families: The systemic costs of caring. (pp. 139-170).

Rokach, A. (1990). Content analysis of sexual fantasies of males and females. Journal of psychology, 124, 427-436. 
Adult and Juvenile Sexual Offenders 91

Russell, D.E.H. (1983). The incidence and prevalence of intrafamilial and extrafamilial sexual abuse of female children. Child Abuse and Neglect, 7, $133-146$.

Russell, D.E.H. (1986). The secret trauma: Incest in the lives of girls and women. New York: Basic Books.

Ryan, G. (1997). Sexually abusive youth: defining the population. In Gail Ryan and Sandy Lane (Eds.), Juvenile sexual offending: Causes, consequences, and correction. San Francisco, CA; Jossey-Bass Publishers.

Ryan, G., \& Lane, S. (1997). The impact of sexual abuse on the interventionist. G. Ryan \& S. Lane (Eds.), Juvenile sexual offending: Causes, consequences, and correction. San Francisco, CA: Jossey-Bass publishers.

Sadoff, R.L. (1975). Treatment of violent sex offenders. International Journal of Offender Therapy and Comparative Criminology: Official Organ of the Association for Psychiatric Treatment of Offenders, 19, 75-80.

Salter, A.C. (1988). Treating child sex offenders and victims: A practical guide.

Schonberg, I.J. (1992). The distortion of the role of mother in child sexual abuse. Journal of Child Sexual Abuse, 1, 47-61.

Seghorn, T., Prentky, R.A., \& Boucher, R.J. (1987). Childhood sexual abuse in the lives of sexually aggressive offenders. Journal of the American Academy of Child \& Adolescent Psychiatry, 26, 262-267. 
Seto, M.C., Maric, A., \& Barbaree, H.E. (2001). The role of pornography in the etiology of sexual aggression. Aggression \& Violent Behavior, 6,35-53.

Shanor, K. (1977). The fantasy files: A study of the sexual fantasies of contemporary women. New York: Dial Press.

Shanor, K. (1978). The Shanor study: The sexual sensitivity of the American male. New York: Dial Press.

Singer, J.L. (1966). Daydreaming. New York: Random House.

Singer, D.G. \& Singer, J. (Eds.). (2001). Handbook of children and the media. Thousand Oaks, CA: Sage Publications, Inc.

Smallbone, S.W. \& Milne, L. (2000). Associations between trait anger and aggression used in the commission of sexual offenses. International Journal of Offender Therapy \& Comparative Criminology, 44, 606-617.

Sue, D. (1979). Erotic fantasies of college students during coitus. Journal of Sex Research, 15, 299-305.

Sutton-Smith, B. \& Abrams, D.M. (1978). Psychosexual material in the stories told by children: The Fucker. Archives of Sexual Behavior, 7(6), 521-543.

Tabacoff, R. (2002). Comparing sex offending and conduct disordered youth: The role of family. Dissertation Abstracts International: Section B: the Sciences \& Engineering, 62(7-B),3404, US: Univ Microfilms International. 
Adult and Juvenile Sexual Offenders 93

U.S. Department of Health and Human Services (1991). Healthy people 2000: National health promotion and disease prevention objectives (DHHS Publication No. (PHS) 91-50213). Washington, DC: U.S. Government Printing Office.

Van Dam, C. (2001). Identifying child molester: Preventing child sexual abuse by recognizing the patterns of the offenders. Binghamton, NY: The Haworth Maltreatment and Trauma Press.

Walker, E.A., Unutzer, J., Rutter, C., Gelfand, A., Saunders, K., VonKorff, M., Koss, M.P., \& Katon, W. (1999). Costs of health care use by women HMO members with a history of childhood abuse and neglect. Archives of General Psychiatry, 56, 609-613.

Wilson, G.D. \& Lang, R.J. (1981). Sex differences in sexual fantasy patterns. Personality and Individual Differences, 2, 343-346.

Witt, P.H., Bosley, J.T., \& Hiscox, S.P. (2002). Evaluation of juvenile sex offenders. Journal of Psychiatry \& Law, 30, 569-592.

Yang, N., \& Linz, D. (1990). Movie ratings and the content of adult videos: The sexviolence ratio. Journal of Communication, 40, 28-42.

Zillman, D. (1971). Excitation transfer in communication-mediated aggressive behavior. Journal of Experimental Social Psychology, 7, 419-434. 
Zolondek, S.C., Abel, G.G., Northey, W.F., \& Jordan, A.D. (2001). The self-reported behaviors of juvenile sexual offenders. Journal of Interpersonal Violence, $16(1), 73-85$. 